\title{
Measuring the spatial accessibility to fire stations using enhanced floating catchment method
}

\author{
Kiran KC*, a, c , Jonathan Corcoran ${ }^{a}$, Prem Chhetrib \\ a Queensland Centre for Population Research, School of Earth and Environmental Sciences, The \\ University of Queensland, Brisbane, Queensland, 4072, Australia \\ ${ }^{b}$ School of Business IT and Logistics, Royal Melbourne Institute of Technology (RMT) University, \\ Melbourne, Victoria, 3000, Australia \\ c Cities Research Institute, Griffith University, Queensland, 4111, Australia \\ * Corresponding Author. E-mail addresses: kiran.kc@uqconnect.edu.au (K.KC), \\ j.corcoran@uq.edu.au (J.Corcoran), prem.chhetri@rmit.edu.au (P.Chhetri).
}

\section{Abstract}

Enhancing the spatial accessibility of population to fire services is a key strategy to help improve emergency response, minimise property loss, and reduce injuries and deaths. Given its significance for fire service policy and strategic planning, we draw on small area population forecasts, fire station locations and the road network, and employ the enhanced two-step floating catchment method to compute the levels of spatial accessibility of population to fire services in relation to current and future population growth in Brisbane, Australia. Results show that lower levels of spatial accessibility to fire services exist in the most populated areas compared to those that are least populated. Further, we reveal that some areas are more likely to suffer a reduction in spatial accessibility than others. Spatial accessibility of population to fire services over the period to 2036 is likely to reduce as a consequence of rising demand for service. The identification of locales that experience lower levels of accessibility to fire services will enable fire services agencies to strategically plan infrastructure investment and help enhance the operational efficiency of emergency response.

\section{Keywords:}

Spatial accessibility; urban fire; floating catchment analysis; population and emergency response 


\section{Introduction}

"On the alarm of fire, he proceeds with all possible speed to the engine-house to which he is attached" (Braidwood 1866, p. 95).

A quick and agile response, are two critical factors that determine the efficiency of operational response to emergency call-outs. Timely response is paramount to ensure the safety of people, and protection of properties and the physical environment (Challands 2010; Murray 2013). Each year, fires cost tens of billions of dollars worldwide, which is estimated to be about one per cent of global GDP and are directly or indirectly linked to 265,000 deaths per year (The Geneva Association 2014; The World Health Organization 2016). For these reasons, a significant amount of public resources are allocated to emergency services agencies to enhance service quality and operational efficiency (Murray 2013). Nonetheless, timely response to calls for emergency services continues to challenge fire agencies, especially in responding to rapidly growing metropolitan areas experiencing significant population growth and restructuring in urban form (Productivity Commission 2015; KC et al. 2015; KC \& Corcoran 2017). The optimal distribution of fire stations that aligns with the changing demand for services is a vital operational tool to maintain timely response with minimum resources.

The identification of the most suitable locations to site fire stations to establish an equitable fire network coverage is a major goal for fire agencies (Rafi et al. 2012). Nevertheless, the methods adopted to site emergency facilities, in addition to the required number of such facilities to achieve Service Delivery Standards (SDS), ${ }^{1}$ differ. The lack of consensus on an appropriate method is attributed to the differences in management goals, operational objectives and the criteria employed to evaluate location choices (Murray 2013; Jennings 2013). Spatial analytics have for some time been used by policymakers and practitioners to capture spatial coverage and geographic accessibility (Hogg 1968; Schreuder 1981; Badri et al. 1998; Farahani et al. 2010; Degel et al. 2011; Catay 2011; Chevalier et al 2012). Many of these studies have employed location models to evaluate the capacity and efficiency of emergency response through linking factors such as cost, time, population/dwelling density, socioeconomic conditions and political interests (Badri et al. 1998; Catay 2011; Chevalier et al. 2012; Degel et al. 2011; Basar et al. 2012; Pérez \& Marianov 2014; Murray 2015). However, a limited number of studies have drawn on estimates of future population growth to inform location decision choices for new fire stations in areas which are likely to generate higher future demands for emergency service (Murray et al. 2013; Aktas et al. 2013; KC et al. 2018).

Previous empirical studies have drawn on a series of methods that have sought to identify ways in which service delivery could be improved. One major suite of methods applied to enhance fire

\footnotetext{
${ }^{1}$ Service Delivery Standards (SDS) is a target imposed by fire agencies and authorities to establish benchmark times for response to a call for emergency service (Chevalier et al. 2012; Productivity Commission 2015).
} 
service delivery belongs to location modelling, which has evolved over the past six decades beginning with the seminal work of Hogg in the 1960s (Hogg 1968). However, what remains less evident from the extant literature on locational models is the ability to incorporate the spatial variability in changing demands for fire service accessibility induced by future population growth. The application of spatial accessibility measures is widely seen in the fields of health (Luo \& Wang 2003) and transport (Langford et al. 2012), however a robust method is now needed to explicitly accountfor the relationship between numbers of facilities and potential demand points for emergency services (Lee 2014; Langford et al. 2016).

Floating Catchment Analysis (FCA) is one such method which measures spatial accessibility to public services such as hospitals (McGrail \& Humphreys 2009; Luo \& Qi 2009), urban parks and green spaces (Dony et al. 2015), sport facilities (Higgs et al. 2015) or bus stations (Langford et al. 2012; Langford et al. 2016). While the FCA method and its various extensions such as the enhanced two-step FCA (E2SFCA) has been applied in a range of fields, its application in emergency services planning remains limited (Lee 2014). FCA has the capability to incorporate both demand (e.g., population size) and supply (e.g., number of firefighting appliances) to measure spatial accessibility to public services. The application of FCA to the emergency services has direct utility in its capacity to generate evidence for strategic planning by identifying suitable locations for fire stations accounting for both current and future demand and supply of fire services.

To address the limitation of traditional measures of spatial accessibility, we employ the FCA method to compute spatial accessibility to fire services using the case study of Brisbane Statistical Division (BSD) in Queensland, a rapidly growing metropolitan city of Australia. FCA has the capability to integrate both elements of coverage and accessibility in the way that the technique simultaneously considers both demand and supply, overcoming the limitations of traditional methods i.e., the assumption of equal access within and no access outside the catchment (Langford et al., 2012). In addition, FCA method allows dealing with the assumption of spatial proximity measures that people use their nearest facility to access a service. Furthermore, the integration of the distance-decay parameter, accounting for the spatial interaction between both demand (e.g., population size) and supply (e.g., fire stations) makes FCA more reliable and accurate (Luo \& Qi 2009).

Drawing on small area population forecasts, this paper, for the first time in Australia, investigates the optimality of fire station locations in relation to both demand and supply. More specifically, the aim of this paper is two-fold: first to examine the levels of spatial accessibility to fire stations in relation to changing spatial distribution of population in the BSD; and second to identify potential fire station locations that have the capacity to enhance timely response to calls for emergency services. 
The remainder of the paper is structured as follows. The next section (Section 2) outlines an overview of the various approaches and methods employed to measure the spatial accessibility of public services. Section 3 describes the case study context, data and our analytic approach applied. Section 4 presents the results before concluding with a summary of the key findings, policy recommendations along with some fruitful avenues for future research in Section 5.

\section{Accessibility: concepts and measurements}

Accessibility is a widely used concept in transport modelling, urban planning, and service delivery management (Reilly 1931; Hansen 1959; Nutley 1980; Pooler 1987; Bhatt et al. 2000; Geurs \& Wee 2004; Langford et al. 2012; Higgs et al. 2015; Dony et al. 2015; Higgs et al. 2017). The seminal work of Reilly (1931) measured the size of retail trade between two cities by drawing trade area boundaries using the distance between the cities and the population of each city. This is referred to as the law of retail gravitation. Subsequent to Reilly's study, scholars have advanced a broad range of empirical studies proposing a variety of different measures of accessibility (see for example, Dalvi \& Martin 1976; Burns 1979; Joseph \& Phillips, 1984; Bhat et al 2000; Scheurer \& Curtis 2007; Luo \& Qi 2009; Curtis \& Scheurer 2010).

\subsection{Accessibility}

Accessibility has been described as "the potential of opportunities for interaction" (Hansen (1959 p. 73) or "the ease of an individual to pursue an activity of a desired type, at a desired location, by a desired mode, and at a desired time" (Bhat (2000) p. 1). Geurs \& Wee in their study define accessibility as "the extent to which land-use and transport systems enable (groups of) individuals to reach activities or destinations by means of a (combination of) transportation mode(s)" (p. 128). Bertolini et al. (2005) define accessibility as "the amount and diversity of places that can be reached within a given travel time and/or cost" (p. 209). Some researchers refer to accessibility as the relative ease by which a destination is reached (BTS 1997; Luo 2004).

There is no single universally agreed definition of accessibility. It is because accessibility is a multidimensional concept which can be applied to measure various aspects or dimensions of accessibility to various amenities including geographic, economic, social or even perceptual. This fit for purpose approach creates ambiguity and thus subjectivity due to the ways the notion of accessibility has been operationalised and interpreted (Bhat et al. 2000; Curtis \& Scheurer 2010). The lack of a theoretically founded definition of accessibility and the confusion of selecting the right measure potentially hinders our ability to select it as a decision tool to aid infrastructure policy-making and operational planning. 
Accessibility can be classified into two groups: (i) spatial accessibility (e.g., geographic location and distance), and (ii) non-spatial accessibility (e.g., social class, income, age and gender) (Joseph \& Phillips 1984; Luo 2004). Both spatial and non-spatial factors and their interactions play an important role in determining the accessibility of, or to reach, the service. Spatial accessibility, in particular, refers to the availability of, and proximity to services (Khan 1992; Joseph \& Phillips, 1984; Luo \& Wang 2003; McGrail \& Humpreys 2009; Lee 2014). McGrail \& Humphreys (2009, p 534) argued that "both availability and proximity need to be measured together when defining spatial accessibility". Geurs \& Wee (2004) identify four components of accessibility, namely: land-use (concerned with the spatial distribution of activities and the relationship between demand and supply of opportunities), transportation (reflecting measures such as travel time and cost and effort of movement in space), temporal (represents time restrictions, availability of activities or services in a time of the day, the day of the week, or the month of the year) and individual (people's income, gender, travel budget, education level), each of which are important in their capacity to measure spatial accessibility.

In general, accessibility is an estimate of what many authors have called 'availability of services' (e.g., ambulance and firefighting services) within a given response time, or the probability of finding an idle vehicle within specified time limits (Larson 1974; Daskin 1983; Jarvis 1985; Hogan \& ReVelle 1986; Batta \& Mannur 1990; Ball \& Lin 1993; Goldberg 2004; Zang et al. 2013). These studies have formulated models under the banner of 'location models' of which there are arguably four broad types that have been developed and applied to emergency service contexts (Marianov \& Serra 2002; Goldberg 2004; Murray 2010; Degel et al. 2011; Murray 2015; KC et al. 2018). The early location models such as Location Set Covering Problem (LSCP) (Toregas et al. 1971) and the Maximal Covering Location Problem (MCLP) (Church \& ReVelle 1974) are deterministic type of location models that aim to maximise a single coverage of a set of demand points by a fleet of vehicles.

Backup coverage models (Daskin \& Stern 1981; Hogan \& ReVelle 1986; Ball \& Lin 1993; Chevalier et al. 2012) belong to the second type that overcomes some of the deficiencies of earlier models by including an objective of maximising the coverage of demand points by more than one vehicle. In other words, these models provide supplementary coverage by a fleet of vehicles (Daskin \& Stern 1981; Chevalier et al. 2012). Probabilistic coverage models (Daskin 1983; Owen \& Daskin 1998; Marianov \& ReVelle 1996; Zang et al. 2013; Pérez \& Marianov 2014) are another type of location model and address the strong assumption made by backup coverage models that is the use of identical busyness probabilities. By employing differentiated busyness probabilities, these models capture a more realistic estimate of resource availability and the impactsituations such as peak hour road traffic conditions on the allocation of a vehicle to a call for emergency service (Marianov \& ReVelle 1996; Pérez \& Marianov 2014; van den Berg \& Aardal 2015). The final type is the hypercube queuing models that consider the spatial distribution as well as the status of vehicles (i.e. these 
models differentiate between both idle and busy vehicles) as well as coordination among the fleet (Larson 1974; Larson 1975; Jarvis 1985; Goldberg \& Paz 1991; Batta et al. 1989; Takeda et al. 2007; Ansari et al. 2017).

In sum, there are a range of location models that enable determining solutions to ascertain optimal locations for emergency service facilities. Most studies however have adopted the covering approach (i.e., to cover the maximum number of demands or populations) to enhance emergency response and improve service quality. While existing studies have shown the advantages of applying location models for fire services location planning, one area that remains subject to little research is the utility of location models to measure the spatial accessibility to fire services in relation to their coverage. Such knowledge is important in its capacity to inform future policy and planning related to fire station location, especially in regions undergoing growth in their population (Murray 2013; Jennings 2013; Murray 2015; KC et al. 2018). A recent body of literature has widely acknowledged the benefits of FCA method for measuring spatial accessibility to public services such as primary health care (Luo \& Wang 2003; McGrail \& Humphreys 2009; Luo \& Qi 2009) and transport opportunities (Langford et al. 2012). The FCA method incorporates a distance decay parameter to account for spatial interaction between both demand (e.g., population size) and supply (e.g., fire stations and number of appliances) to measure the spatial accessibility of fire services. Furthermore, the application of FCA has the capacity to integrate both elements of coverage and accessibility, which we discuss in more detail in Section 2.2. Next, we review the studies on measures of spatial accessibility, highlighting the potential for fire service planning.

\subsection{Measuring spatial accessibility}

The concept of spatial accessibility is different to accessibility. Accessibility could have a social or psychological dimension. Spatial accessibility denotes an explicit geographic focus. Broadly, spatial accessibility measures can be categorised into four major groups, namely (1) proximity ; (2) regional availability; (3) gravity models; and (4) floating catchment analysis (Hansen 1959; Ingram 1971; Vickerman 1974; Nutley 1980; Bruinsma \& Rietveld 1998; Bhat et al. 2000; Guagliardo 2004; Luo 2004; Bagheri et al. 2006; Langford \& Higgs 2006; Scheurer \& Curtis 2007; McGrail \& Humphreys 2009; Curtis \& Scheurer 2010; Luo \& Whippo 2012; Lee 2014; Higgs et al. 2015; Dony et al. 2015; Langford et al. 2016; Higgs et al. 2017; Frew et al. 2017). Table 1 presents a brief overview of all four measures. 


\section{Mēäsürère}

Proximity

\section{Approach}

(Ingram 1971; Nutley 1980; between an origin and a destination.

Bhat et al. 2000)

\section{Pros and cons}

Simple to operationalise and interpret. Basic data requirements.

Flexibility in providing choices of different measures (distance, time, cost or convenience). Accounts for the time or distance between origin and destination.

Basic and rudimentary approach, No consideration of land use variability or spatial interactions, spatial homogeneity in service availability

\section{-Regional availability The spatial distribution of supply and Accounts for the availability of services. Simple to operationalise and} (Bruinsma \& Rietveld 1998; demand nodes within a region.

Bhat et al. 2000; Scheurer \&

Curtis 2007)

interpret. Relatively fewer data hungry.

The problem of selecting the ideal administrative unit for measuring accessibility. Ignore land-use variability and spatial interactions. Intraregional variability Problem

\section{Gravity models}

(Reilly 1931; Hansen 1959; Vickerman 1974; Weibull 1976; Joseph \& Phillips 1984; Bhatt et al. 2000; Yang et al. 2006)
Defines catchment areas by measuring Captures both proximity and availability of services. Incorporates travel time or distance impediment on a spatial interactions between locations using a distance-decay function continuous surface or discrete boundaries.

(i.e., accounts for travel resistance).
Relatively difficult to operationalise and interpret. Hard to derive a distance decay function based on empirical data. Difficult to estimate, as it requires iterative estimation procedure. Allows the trade-off between the number of servers (e.g., fire trucks, or a number of doctors) and travel time. 


\section{Floating catchment analysis}

(Luo \& Wang 2003; McGrail \& Humphreys 2009; Luo \& Qi 2009; Wan et al. 2011; Luo \& Whippo 2012; Dony et al. 2015; Langford et al. 2016; Higgs et al. 2015; Higgs et al. 2017)
Defines catchment areas by measuring travel time or distance on a continuous scale using floating catchment areas or windows instead of set boundaries. Estimates the accessibility of services in area $i$ to other areas $(n)$ in which more distant services provide diminishing influences.

Addresses two general assumptions such as equal access within a catchment and no access outside a catchment (binary relation).

The enhanced FCA measure considers distance decay by travel time zones, thereby accounting for distance-decay to maintain a theoretical association with the gravity model. The enhanced FCA measure considers the capacity of both supply side (e.g., number of appliances), and demand side (e.g., population). Easy to operationalize. Results from this measure are simple and easy to interpret. 
The proximity to the nearest facility is a traditional method for measuring spatial accessibility (Ingram 1971). It is also the most common method (Bhat et al. 2000), which simply measures the distance or the time taken to reach the nearest facility (Luo 2004; Langford et al. 2012). Proximity measures are popular in urban studies due to their ease of operationalisation, interoperability, and communicability criteria (Wang 2003; Geurs \& Wee 2004). The least complex measure of proximity is the Euclidean distance between two points, yet proximity measures often focus on travel or time distance, congestion and operating cost on a transportation network for infrastructure-based accessibility (Albacete 2017). Although this measure considers the proximity to services, it does not consider whether the services are available at a specific facility. More specifically, this measure neither considers the capacity of the service station (e.g., number of appliances) nor does it consider the size of the demand (e.g., population). Proximity measures assume that individuals use their closest facility to access a particular service. This measure likewise does not consider the spatial distribution of the demand for the service and does not take into account individuals' perceptions and preferences.

The regional availability methods measure the distribution of supply versus demand within a region often expressed as a demand-to-supplier ratio within a given region (Bruinsma \& Rietveld 1998; Bhat et al. 2000; Scheurer \& Curtis 2007; Curtis \& Scheurer 2010). This measure offers an element of choice for services or activities with the given conditions of time and transport (Higgs et al. 2017), as well as taking into account the capacity of the service provider or the size of the population (Albacete 2017). Regional availability is acknowledged as the simplest measure to identify public services undersupply in a region, for example, primary health care (Luo 2003). The use of the region typically employs de jure units such as census boundaries (Luo 2004). While this method has wide application in measuring spatial accessibility to public services, this method is often criticised for the problem of selecting the most appropriate administrative unit deemed suitable for emergency planning. The problems associated with predefined administrative boundaries in assessing accessibility are well recognised, yet not resolved. This is mainly because both demands and supplies are spatially distributed and are more likely overlapping creating competition between supply and demand (Luo 2004; Luo and Qi 2009).

The gravity model measures the interaction between two objects based on their mass and distance from one another (Reilly 1931; Joseph \& Kuby 2011). The gravity model is widely used in accessibility studies (Bhatt et al. 2000; Yang et al. 2006). Gravity-based measures reveal the spatial variations of accessibility within service areas, thereby addressing the drawbacks of traditional measures of spatial accessibility. Specifically through considering both proximity and availability of services (Joseph \& Phillips 1984), the gravity model captures the spatial interaction between both supply and demand located within different regions using a distance-decay function (a function that 
measures the declining tendency of accessibility with increasing distance or travel time) (Weibull 1976; Joseph \& Phillips, 1984; Guagliardo 2004; Yang et al. 2006). Although the gravity model seems to be a conceptually complete measure of spatial accessibility, Luo \& Wang (2003) argue that it is less intuitive to interpret the results, and it is data-driven and computation-intensive (Luo \& Qi 2009). Further, this model considers the capacity of only supply side (e.g., number of appliances), but not demand side (e.g., population). Empirical studies have also argued the difficulty in determining the distance-decay function (Guagliardo, 2004; Joseph \& Phillips, 1984). McGrail \& Humphreys (2009) state that overemphasis of the distance-decay function also leads to heavily spatially smoothed results (Luo \& Wang 2003). Most of all, the most significant limitation of the gravity-based method is that it allows the trade-off between the number of servers (e.g., appliances such as fire trucks, ambulances or number of doctors in a hospital) and travel time (Luo \& Wang 2003). Although the gravity-based method defines accessibility as a continuous measure in the form of a surface or grid, its application to the emergency services often represents accessibility as a dichotomous measure (Luo \& Qi 2009).

The floating catchment analysis method measures the spatial accessibility of population to public services. Typically, the FCA method can be used to identify the spatial variability in demand (population) and supply (provider) for services across areas. The FCA method has most of the advantages of the gravity-based method, easy to use and simple to interpret. Furthermore, the FCA method also takes into account the spatial interaction between population and service providers across administrative boundaries based on specified travel times or distance. The key feature of this method is its ability to account for spatial heterogeneity in demand (Luo \& Wang 2003; Luo \& Qi 2009). An early version of the FCA method was employed in assessing accessibility to employment hubs (Peng 1997).

Building on earlier versions of FCA (Peng 1997; Radke \& Mu 2000; Wang \& Minor 2002), Luo \& Wang (2003) developed a two-step FCA (2SFCA) method in the application of identifying physicianshortage areas in Illinois. The 2SFCA method is a special case of the gravity-based method as it captures accessibility as a dichotomous measure and uses floating catchment areas or windows rather than set boundaries. McGrail \& Humphreys (2009) employed 2SFCA method to measure spatial accessibility to primary care service for the rural population of Victoria, Australia. They found variations in the pattern of spatial accessibility using 2SFCA method, which was not detected by previous versions of FCA methods. Further, the 2SFCA method has been used in the number of studies assessing health care accessibility (e.g., Dai 2010, Schuurman et al. 2010, Ngui \& Apparicio, 2011). Luo \& Qi (2009) noted the limitations of 2SFCA method and developed the E2SFCA method by assigning geographical weights in both steps of the calculation process to differentiate travel time zones, thereby accounting for distance-decay (for distance-decay they adopted the discrete stepped 
function) to maintain theoretical association with the gravity model. In their study of measuring spatial access to primary care physicians in northern Illinois, Luo \& Qi considered multiple distance decay by travel time zones to differentiate accessibility within the catchment, substituting the dichotomous 0 and 1 as in 2SFCA.

Increasingly, FCA method and its extensions have been used to measure spatial accessibility in various health applications, for example; physician services (Luo \& Whippo 2012); colorectal services (Wan et al. 2011); primary health care services (McGrail \& Humphreys 2009; Ngui \& Apparicio 2011). Other applications include non-health services such as public parks (Dony et al. 2015); employment (Wang 2000; Wang \& Minor 2002); food stores (Dai \& Wang 2011); sport facilities (Higgs et al. 2015); ambulance services (Lee 2014); and transport opportunities (Langford et al. 2012). In particular, Dony et al. (2015) modified the 2SFCA method to examine disparities in access to public parks in Mecklenburg County, North Carolina. They developed a Variable-width Floating Catchment Area (VFCA) method to compare accessibility to public parks using four modes of transportation: bicycling, driving, public transit, and walking. Their findings show that access to parks by walking to be lowest throughout the county compared to other modes of transportation, and access to greater regional parks is greatest for outer suburban areas, and people living in the centre of the City have access to a greater number of park facilities.

More recently, Langford et al. (2012) modified E2SFCA methodology to examine intra-urban variations in accessibility to public transport opportunities in the City of Cardiff and Wales. Langford et al. (2012, p. 4) developed a 'VB.NET/ArcObjects application' and examined the overall trend of accessibility with increasing levels of deprivation using three alternatives for distance-decay, namely (i) linear decay; (ii) no decay; (iii) and Butterworth decay (Figure 1). Based on their findings, they argued that the Butterworth decay function (Butterworth 1930) generate the smoothest trend and also gave rise to the greatest contrast in accessibility between the least and most deprived classes.

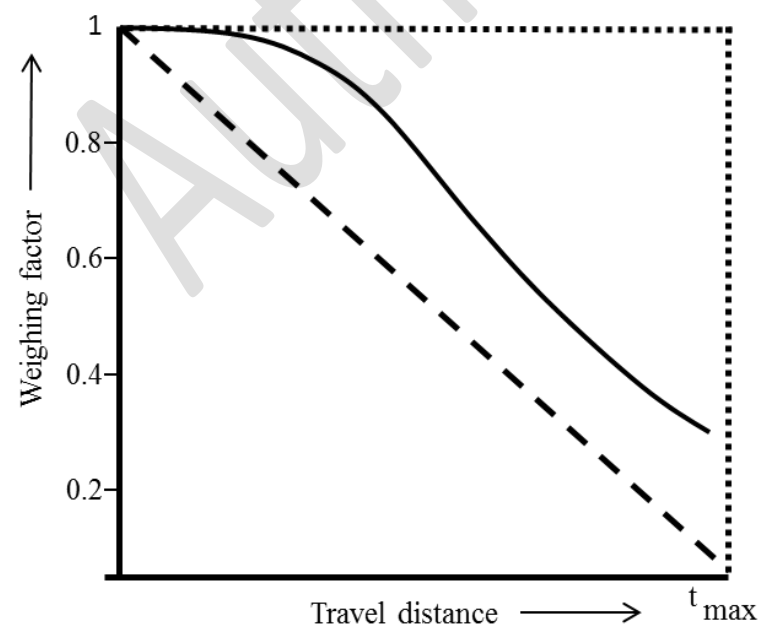

Figure 1 Linear decay (dashed), no decay (dotted), and Butterworth distance decay (solid line) (Source: Langford et al. 2012, p. 4). 
To conclude, while there is an increasing use of FCA, there has been little research in the application of the FCA method to measure spatial accessibility to emergency services (Lee 2014). More importantly, there has been no empirical study that has used the FCA method to examine the spatial variability of fire services accessibility and its variation over time. The majority of existing studies on fire service location planning have used location models to identify whether the demand for services is covered or not (i.e., as a binary outcome) by a fire station based on its SDS, however, it has not been used to examine how accessible such locales are to fire services in relation to their coverage. We therefore employ the FCA method to generate a new evidence base for fire service agencies with the capacity to identify fire service station locations in relation to both current and future demand for services. To this end, the value of the FCA method for location modelling are that it:

○ integrates both the elements of location coverage (i.e. travel time to nearest fire station; the number of fire stations within a specified travel time), and spatial accessibility of the resident population to fire services; and,

- addresses the limitation of the assumption of equal access by some traditional location modelling approaches within a given catchment and no access at all outside a catchment); and,

o incorporates a distance-decay parameter and accounts for the spatial interaction between demand (e.g., current and future population) and supply (e.g., fire stations and number of appliances) across administrative boundaries based on travel times; and,

- computes metropolitan-wide accessibility scores, which forms an evidence base for location planning of fire stations such as prioritising areas of low fire service accessibility.

\section{Research methodology}

This section presents an overview of the study area, data sources and the analytic approach.

\subsection{Study area and datasets used}

Brisbane, the capital of Queensland in Australia with a population over two million, forms the case study context for this study (Figure 2). The city accounts for approximately 12.53 per cent of the total population growth in the State (ABS 2014), with inter-state migration and immigration being the major drivers of population growth (Chhetri et al. 2018; Chhetri et al. 2009; ABS 2014). Covering a total of 5,950 square kilometres area, the Brisbane Statistical Division (BSD) continues to experience relatively rapid infrastructure (re)development, urban densification and population growth (Krockenberger 2015). 


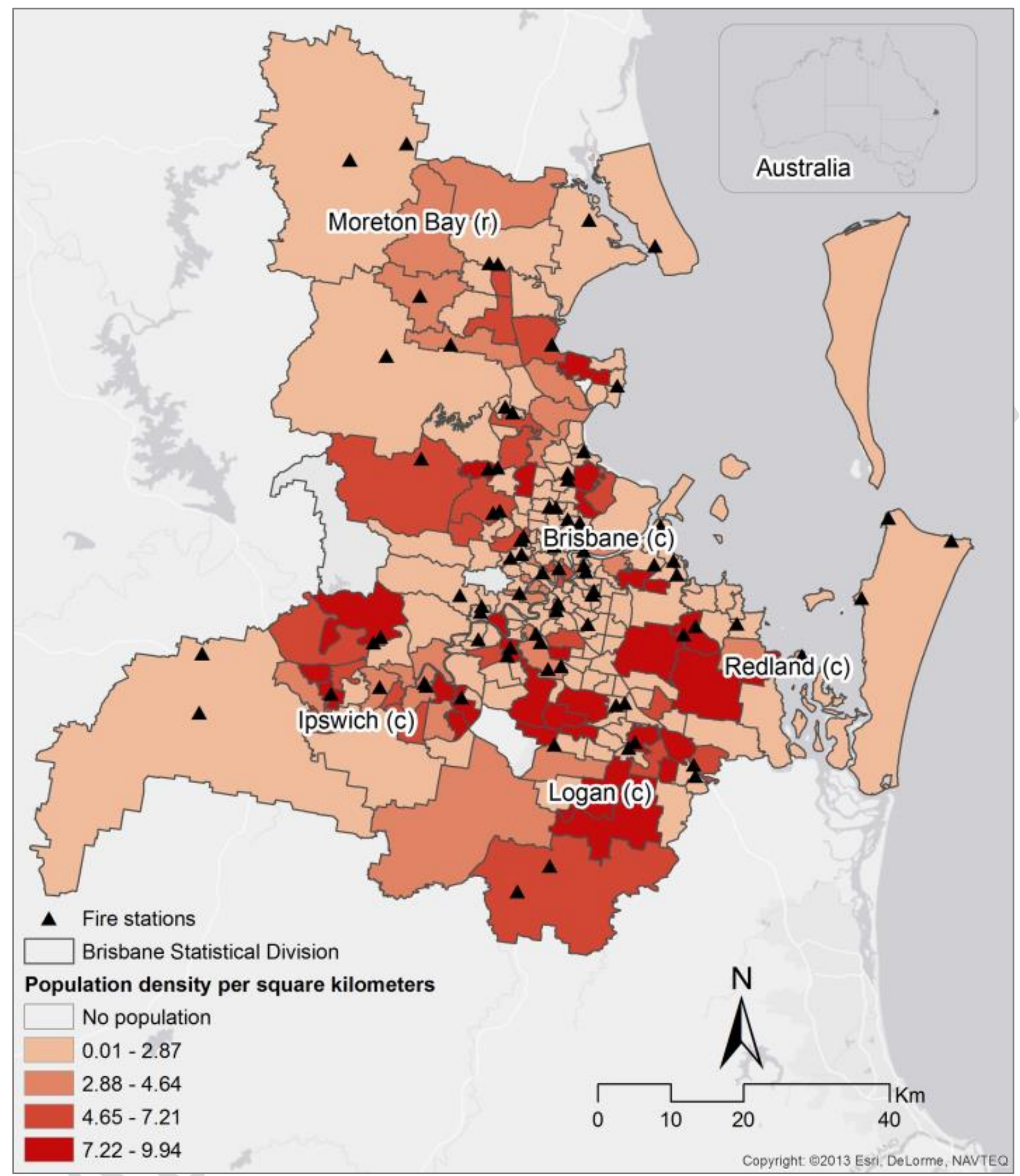

Figure 2 Brisbane Statistical Division (BSD), fire stations and distribution of population

In this study, a range of datasets are obtained from a variety of sources. To examine the spatial patterns of fire service accessibility in the BSD, four formerly disparate data sets are integrated into a single spatial database. Table 2 lists the data sets used, their sources and a brief description. 
Table 2 List of data, source and their description

\begin{tabular}{|c|c|c|}
\hline D̄ata & Source & Description \\
\hline $\begin{array}{l}\text { Fire station } \\
\text { locations }\end{array}$ & $\begin{array}{l}\text { Queensland Fire and } \\
\text { Emergency Services } \\
\text { (QFES) }\end{array}$ & $\begin{array}{l}\text { format by QFES, where each record contains the } \\
\text { location (latitude and longitude) and characteristics } \\
\text { (station type, station name, station id, number of } \\
\text { appliances and address) of each fire station. }\end{array}$ \\
\hline $\begin{array}{l}\text { Census } \\
\text { data }\end{array}$ & $\begin{array}{l}\text { Australian Bureau of } \\
\text { Statistics (ABS) }\end{array}$ & $\begin{array}{l}\text { Census data are drawn from the } 2011 \text { census at the } \\
\text { Statistical Area Level } 2\left(\mathrm{SA}^{2}\right) \text { boundaries. }\end{array}$ \\
\hline $\begin{array}{l}\text { Population } \\
\text { forecasts }\end{array}$ & $\begin{array}{l}\text { Queensland } \\
\text { Government } \\
\text { Statistician's Office } \\
\text { (QGSO), Queensland } \\
\text { Government }\end{array}$ & $\begin{array}{l}\text { Population forecast data (medium-series projection), } \\
\text { containing the count of people across five years age } \\
\text { groups, was obtained at a SA2 level. The } \\
\text { Queensland regional population projections ( } 2011 \text { to } \\
2036 \text { at five-year intervals) were obtained from } \\
\text { QGSO for the BSD (Queensland Treasury 2014). }\end{array}$ \\
\hline $\begin{array}{l}\text { Road } \\
\text { network }\end{array}$ & $\begin{array}{l}\text { Department of } \\
\text { Transport and Main } \\
\text { Roads (DTMR), } \\
\text { Queensland } \\
\text { Government }\end{array}$ & $\begin{array}{l}\text { The road network of } 2014 \text { for BSD was acquired in a } \\
\text { GIS format, which contains all State-controlled roads } \\
\text { and other non-state-controlled roads, and the } \\
\text { associated the legislated speed limits. }\end{array}$ \\
\hline
\end{tabular}

\subsection{Analytic approach}

Our analytic approach comprises two parts. The first part examines the current level of fire service accessibility in the BSD. More specifically, we examine the relationship between fire service accessibility measures and the population of the 2011 census at the SA2 level. Our spatial unit of analysis is the SA2 given the availability of population data available at this spatial scale. Further, we present correlation tests between census-derived population data, residential fire response time, and the fire service accessibility metrics.

The second part involves examining future fire service accessibility using population forecasts up to 2036 at a five-year interval. We incorporate future demand emerging from population growth as predicted by QGSO, across the SA2's of the BSD. Further, we employ quadrant plots to depict the relationship between FCA scores and population growth estimates for the period 2011 to 2036 in

\footnotetext{
2 The SA2 is the lowest level of the Australian Statistical Geography Standard (ASGS) structure for which Estimated Resident Population (ERP), Health and Vitals and other non-Census ABS data are generally available (ABS 2011). SA2s have a population range of 3,000 to 25,000 persons, with an average population of about 10,000 persons. In urban areas, SA2s corresponds to suburbs; accordingly, largely comparable to Super Output Area (SOA) in the UK census.
} 
order to identify areas that are most populated and experience lower levels of fire service accessibility.

In this study, we employ the E2SFCA method to generate fire service accessibility scores for each $\mathrm{SA} 2$ in the BSD. The accessibility scores are generated in two steps.

Step 1: The response-time catchments are computed around the supply points (i.e., existing fire stations) and using service volume (i.e., based on the number of fire trucks) and the catchment population (i.e., based on centroids falling inside the area) a supply (fire truck) to demand (population) ratio $\left(R_{\mathrm{j}}\right)$ is computed as follows:

$$
\mathrm{R}_{\mathrm{j}}=\frac{\mathrm{s}_{\mathrm{j}}}{\sum_{\mathrm{k} \in\left\{\mathrm{d}_{\mathrm{kj}} \leq \mathrm{d}_{\max }\right\}} \mathrm{P}_{\mathrm{k}} \mathrm{W}_{\mathrm{kj}}}
$$

Where, $P_{k}$ in equation 1 is the population of a locale $k$ falling within catchment $j\left(i . e_{.}, d_{k j} \leq d_{\max }\right), S_{j}$ the number of fire trucks at location $j, d_{k j}$ the response time between $k$ and $j$, and $d_{\max }$ the response time zone within the catchment. $W_{k j}$ is the distance weight for the specified time zone calculated from the suitable distance decay function, capturing the distance decay of access to the fire services $j$. The distance decay function incorporates the concept as the distance between fire station and population centroid increases, it becomes less likely for people located there to get access to it. Following the methodology presented by Langford et al. (2012), we experiment three distance decay parameters, namely (a) no decay, (b) linear decay, and (c) Butterworth filter decay in order to determine the suitable function that represents the declining tendency for access to fire services.

Step 2: The response-time catchments are created around demand points (i.e., SA2 populationweighted centroids), and fire service accessibility is measured by summing all $R_{j}$ values found in this zone as follows:

$$
\mathrm{A}_{\mathrm{k}}=\sum_{\mathrm{k} \in\left\{\mathrm{d}_{\mathrm{kj}} \leq \mathrm{d}_{\max }\right\}} \mathrm{R}_{\mathrm{j}} \mathrm{w}_{\mathrm{kj}}
$$

Where, $A_{k}$ in equation 2 represents the accessibility of population at location $i$ to fire trucks, $R_{j}$ the fire trucks to population ratio at fire truck location $j$ that falls within the catchment centred at population $i$ (i.e., $d_{k j} \leq d_{\max }$ ), and $d_{i j}$ the response time between $i$ and $j$. $W_{k j}$ the distance decay factor as described earlier.

The accessibility measure reflects availability (i.e., fire trucks to population ratios) and cumulative service accessibility (i.e., the sum of all supply point scores within a given response-time of the demand centre), returning higher values as accessibility increases. As such, the FCA method is a proxy for a 'timely response' given that FCA computes an accessibility score accounting for the 
availability of services and their capacity to provide service within the given response-time, whilst recognising that a 'timely response' is also contingent on other situational factors such as time of day, topographical variability and weather conditions.

Figure 3 shows a schematic illustration of the two-step enhanced FCA method. For illustration purpose, let us assume each locale (i.e., SA2) has only one person and only one appliance (i.e., fire truck) in each fire station location and a response time threshold of 14 minutes $^{3}$ (i.e., catchment area). Using this assumption, in the first step, the catchment of fire station ' 11 ' includes 11 persons and 1 fire truck and thus the fire truck to population ratio is $1 / 11$. Similarly, the ratio at catchment 'j2' is $1 / 10$. In the second step, the ratio for each SA2 can be determined similarly by moving the 14 minutes response time catchment from one SA2 to another (hence the name floating catchment). In the actual calculation, the number of appliances is the sum of the appliances of each fire stations that fall within the 14 minutes response time catchment and the population is the sum of each SA2's population whose centroid falls inside the 14 minutes response time catchment. $A R_{j}$ score is listed for each fire station, and the final accessibility score is the sum of these values for each SA2.

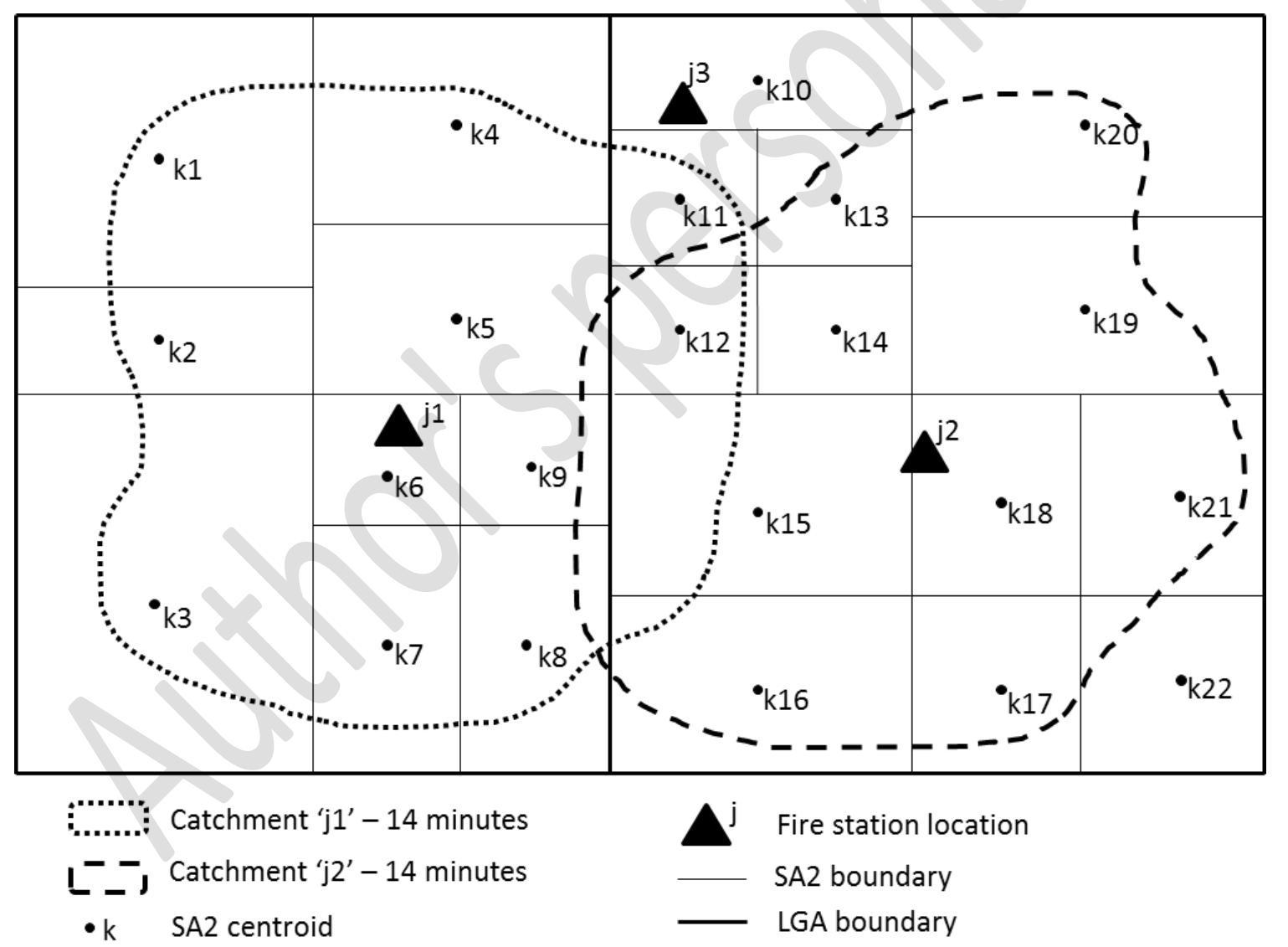

Figure 3 The enhanced two-step floating catchment method

\footnotetext{
3 The 14 minutes response time includes a 2 minute mobilisation period (Emergency Services Computer Aided Dispatch (ESCAD) and turnout time (i.e., time to get ready to get out the door)) and 12 minutes of actual drive time.
} 


\section{Results and analysis}

\subsection{Modelling current levels of fire service accessibility and coverage}

Figure 4 shows the distribution of population quintiles by SA2 across the BSD. Results show that of 230 SA2s in the BSD, 4 (1.74 per cent) locales are found to have no access to a fire station (or not covered) within 14 minutes network response distance of the population-weighted centroid. Although these locales are not subject to SDS (i.e., they are located outside of the current QFES levy boundary ${ }^{4}$ ), results reveal that 2 locales are in the second most populated quintile and that this might form the focus for future resource allocation. Furthermore, the average population of SA2s without a fire station within 14 minutes is 5,840 compared to the BSD-wide average of 9,058 and an average of 9,115 for those SA2s that did possess a fire station within the 14-minute response time threshold.

The analysis of fire incident response times over a 13-year period (1998 to 2013) using historic command and control data shows that there are important spatial variations in response to calls for emergency services across the BSD. There is also some evidence to suggest that it might not always be the closest fire station responding to calls for emergency service (QFES, 2014). More specifically, analysis revealed that 59 per cent of residential fires were responded to (as determined by the first arriving fire appliance) by the geographically most proximate fire station (KC and Corcoran 2017). 41 per cent of incidents were not responded to by their geographically most proximate fire station however were still responded to within the standard response time (i.e. 14 minutes). Further analysis of these 41 per cent of incidents show that these calls for service were ostensibly located within the inner suburbs of the BSD, in locales with higher densities of both fire stations and populations. This might also indicate higher levels of coordination, response synchronisation and cross-collaboration between fire stations within higher density inner city suburbs.

Moving forwards, the FCA analysis conducted in the remainder of this paper is founded upon the assumption that it is the geographically most proximate fire station that responds to a call for service. Analysis of historic command and control data reveals that this might not always be the case, however what we present in this paper is the 'best case scenario'. Indeed, the methods employed here could be adapted to explore the implications of the next nearest station responding to calls for emergency services.

\footnotetext{
${ }^{4}$ The fire lew boundary is delivered and determined by QFES. The SDS measures (i.e., 90 per cent coverage within 14 minutes response time) for examining the spatial patterns of fire service coverage are only applied to areas within the urban fire levy boundary. The urban fire levy is a scheme introduced in 1984 to partially fund the QFES. The scheme is administered through the Fire and Emergency Services Regulation 2011, which applies a fire lew on certain property and places a legal obligation on local governments to collect the lew.
} 


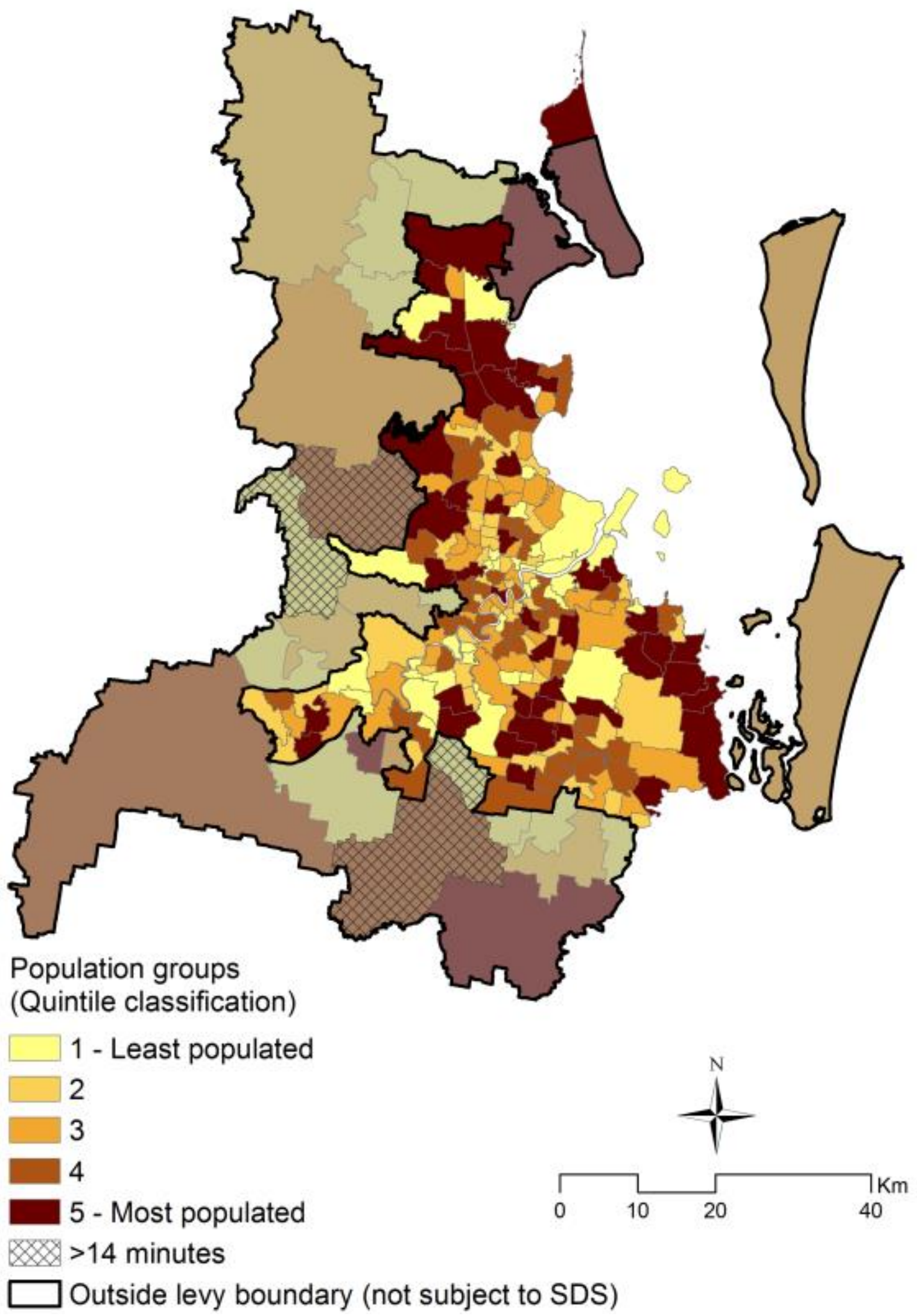

Figure 4 Distribution of population group (quintile)

The relationship between population groups (quintile class), ranging from least to most populated areas, and the set of fire service accessibility measures (i.e., time to the nearest fire station, number 
of fire stations within 14 minutes response time threshold, and E2SFCA score) is shown in both Table 3 and Figure 5. In terms of time (i.e., minutes) to the nearest fire station, Table 3 shows an increasing trend of mean time taken to reach out to emergency calls with the population quintile. This is specially the case for the mean and maximum times to the nearest fire station particularly from the $2^{\text {nd }}$ quintile, with a small reversal in trend for mean time to the nearest fire station from the $4^{\text {th }}$ quintile. Results show that the mean time to the nearest fire station in the most populated locales was 3.83 minutes, compared to 3.26 minutes in the second least populated locales; whilst the maximum time taken from the nearest fire station was 8.59 minutes and 7.48 minutes in the most populated and second least populated locales respectively. Furthermore, the box plots show a consistent variability in travel time with population quintiles. In the case of the number of fire stations (i.e., stations located within the 14 minutes of response time threshold), there was a declining trend of the average number of stations with population quintiles. This is the case for both the mean and minimum number of stations, particularly from the $2^{\text {nd }}$ quintile. On an average, there were 7 stations located in the least populated locales compared to only 6 stations in the most populated locales. These findings show that individuals in the most populated areas were less served by fire stations compared to those living in the least populated locales in the BSD. This could be attributed to traffic conditions, restricted road designs and configurations and limited access to the site.

Table 3 also shows the relationship between population groups (quintile class) and E2SFCA scores calculated through using the Butterworth distance decay method. Results further reiterate the previous finding that locales with the least population in the BSD were better served than the most populated locales. In other words, locales that are most populated have the lowest level of fire service accessibility compared to locales that are least populated. Similarly, the box plots in Figure 5 show a decreasing level of accessibility to fire services with increasing levels of population. This is particularly so for the mean and maximum FCA scores from the $1^{\text {st }}$ quintile, with a small reversal in trend for both from the $5^{\text {th }}$ quintile. 
Table 3 Mean (minimum, maximum) levels of fire service at SA2 area level by population quintile

\begin{tabular}{|c|c|c|c|}
\hline $\begin{array}{l}\text { Population } \\
\text { groups }\end{array}$ & $\begin{array}{l}\text { Time to nearest fire } \\
\text { station (minutes) }\end{array}$ & $\begin{array}{l}\text { Number of fire stations } \\
\text { (within } 14 \text { minutes) }\end{array}$ & $\begin{array}{l}\text { E2SFCA - Butterworth } \\
\text { decay }\end{array}$ \\
\hline $\begin{array}{l}1 \text { - Least } \\
\text { populated }\end{array}$ & $3.94(0.34,9.73)$ & $7(0,12)$ & $0.060(0,0.670)$ \\
\hline 2 & $3.26(0.19,7.48)$ & $8(1,13)$ & $0.053(0008,0.285)$ \\
\hline 3 & $3.58(0.59,9.18)$ & $7(1,12)$ & $0.047(0.009,0.229)$ \\
\hline 4 & $4.07(0.72,9.89)$ & $6(0,12)$ & $0.038(0,0.100)$ \\
\hline $\begin{array}{l}5 \text { - Most } \\
\text { populated }\end{array}$ & $3.83(0.74,8.59)$ & $6(0,13)$ & $0.050(0,0.180)$ \\
\hline
\end{tabular}

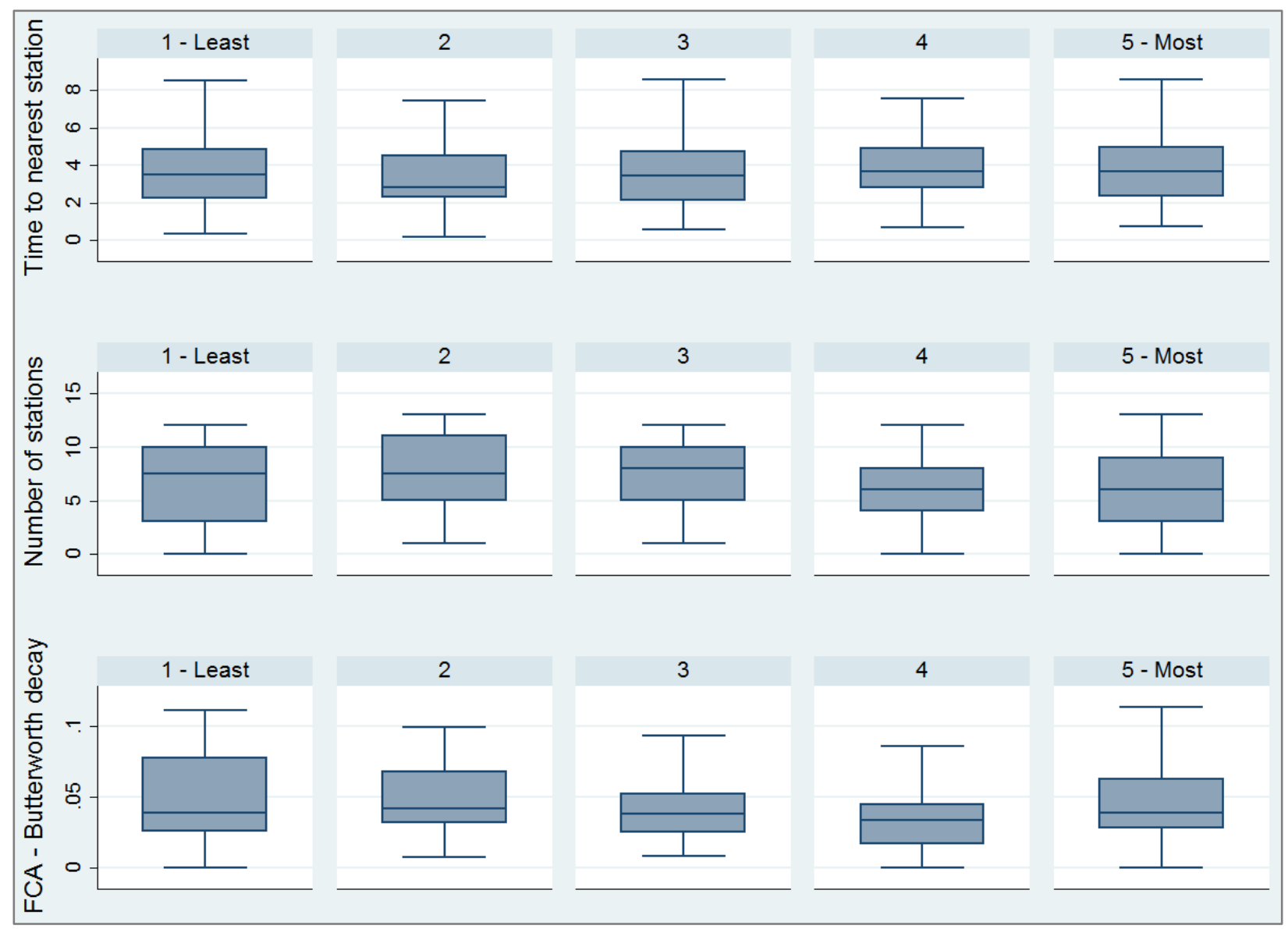

Figure 5 Variations in access measures within population quintile (where, 1 is least populated and 5 is most populated)

Table 4 shows results from correlation tests between census-derived population data, residential fire response time, and the fire service accessibility metrics. Results from this test show that locales that experienced longer response times had the least number of stations, and were least accessible to fire services compared to locales that received fast responses from fire services. Furthermore, Table 4 shows that the traditional accessibility metrics such as number of fire stations (i.e., stations within 
the 14 minutes response time threshold) have a significant negative correlation with population and response times, whereas the FCA-based measure shows a significant negative correlation with response times and a negative correlation with population.

Table 4 Correlation coefficients between SA2 areas, 2011 census data, residential fire response time, and access measures

\begin{tabular}{llll} 
& $\begin{array}{l}\text { Time to nearest } \\
\text { fire station } \\
\text { (minutes) }\end{array}$ & $\begin{array}{l}\text { Number of } \\
\text { fire stations (within 14 } \\
\text { minutes) }\end{array}$ & $\begin{array}{l}\text { E2SFCA score } \\
\text { (Butterworth decay) }\end{array}$ \\
\hline $\begin{array}{l}\text { Population } \\
\text { Residential fire response }\end{array}$ & 0.075 & $-0.113^{*}$ & -0.057 \\
time & $0.387^{* \star *}$ & $-0.421^{* * *}$ & $-0.169^{* *}$ \\
\hline
\end{tabular}

The Butterworth decay function generated the smoothest trend and also gave rise to the greatest contrast in scores between the least and most populated quintiles. Figure 6 illustrates the distribution of the fire service accessibility scores (generated through using Butterworth decay) in the BSD. The figure shows spatial heterogeneity in fire service accessibility in the BSD. Figure 6 shows a visual association of high scores in inner Brisbane where there is high population density. However, this could be due to the large number of stations located in the inner Brisbane area, contributing to faster responses in these areas. As shown in Figure 6, there is clearly some association of low scores in locales around the southern areas of the BSD, which correspond to locales with a large number of people and fewer fire stations. Although most of these locales are not subject to SDS (i.e., outside current fire levy boundary), the findings from the analysis presented above indicate the need for targeted allocation of fire resources in such areas. 


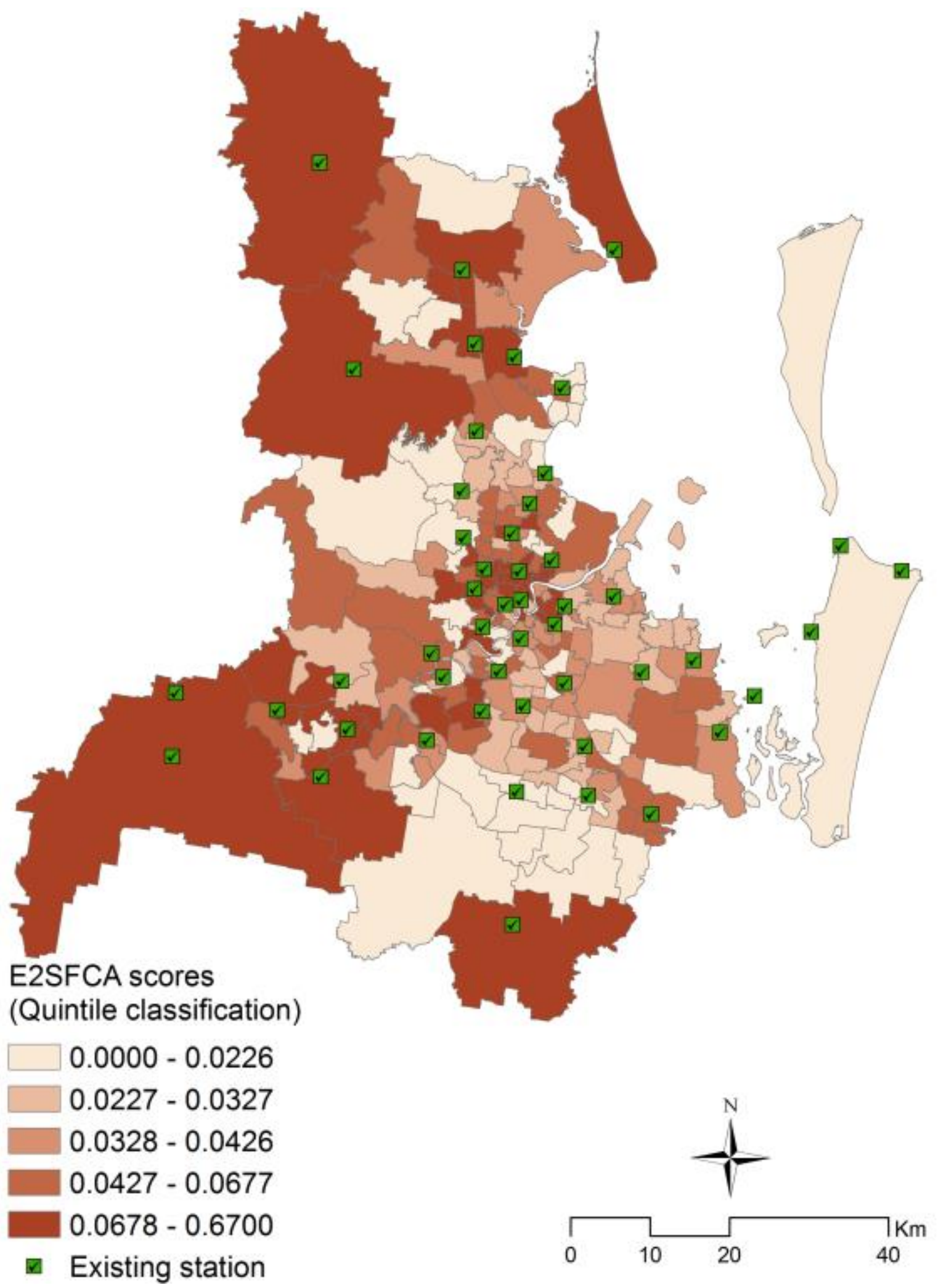

Figure 6 Distribution of E2SFCA scores (Butterworth decay) - 2011

To conclude, results revealed the prevalence of a systematic spatial pattern of association between fire service accessibility measures and population. While the population of the 2011 census exhibited a strong systematic pattern of association with the FCA measure, population estimates is used for further examination on future fire service accessibility in the BSD reported in the next section. 


\subsection{Future fire service accessibility}

The quadrant plots shown in Figure 7 present the relationship between FCA scores and the population estimates for the period 2011 to 2036, where the FCA scores for each locale were computed using the 14-minute response time threshold. The vertical axis in Figure 7 represents the standardised value of fire service accessibility scores; the horizontal axis represents the standardised value of population estimates.

The lower right quadrant (quadrant 1) labelled 'High Pop - Low FCA' represents those locales with a high population and low fire service accessibility in the BSD. Amongst all four quadrants, the locales that fall in quadrant 1 are of greater importance as they provide fire service agencies and planning authorities with information on areas in which future fire service response programs can be improved. Figure 7 shows an increase in the number of locales across census years (i.e., from 2011 to 2036) in quadrant 1 (i.e., locales with high populations and low fire service accessibility). Results reveal the greatest level of contrast in the number of locales between the 2011 and 2036 censuses. For example, of 230 locales in the BSD, 72 (31.3 per cent) were found to be in quadrant 1 in 2011, which increases to 138 (60 per cent) in 2036.

The upper left quadrant (quadrant 3) labelled 'Low Pop - High FCA' represents those locales that contain low population and high fire service accessibility in the BSD. As shown in Figure 7, there is a decreasing trend in the number of locales from 2011 to 2036 (e.g., there were 46 (20 per cent) locales in 2011, which further decreases to 15 (6.54 per cent) in 2036). Furthermore, Table 5 shows the number (per cent) of locales that transition from 2011 quadrants to 2036 quadrants. Of interest to fire services and planning authorities are locales that previously were in quadrant 3 (i.e., locales with low populations and high fire service accessibility) that transition to quadrant 1 (i.e., locales with high populations and low fire service accessibility) as it highlights the urgency of strategically targeting such areas to establish new fire stations. As shown in Table 5, 10 (4.35 per cent) locales particularly in the Southern part of the BSD are found to transition from quadrant 3 to quadrant 1 from 2011 to 2036. Similarly, Figure 7 shows the transition of these locales across all quadrants represented by red dots. The potential locales for future fire stations is visually depicted in Figure 8 .

The other two quadrants labelled 'High pop - High FCA' and 'Low pop - Low FCA' (i.e., quadrants 2 and 4) show a decreasing trend in the number of locales from 2011 to 2036 . However, these quadrants are of low importance as they represent locales that have 'high population and high fire service accessibility' and 'low population and low fire service accessibility', respectively. 


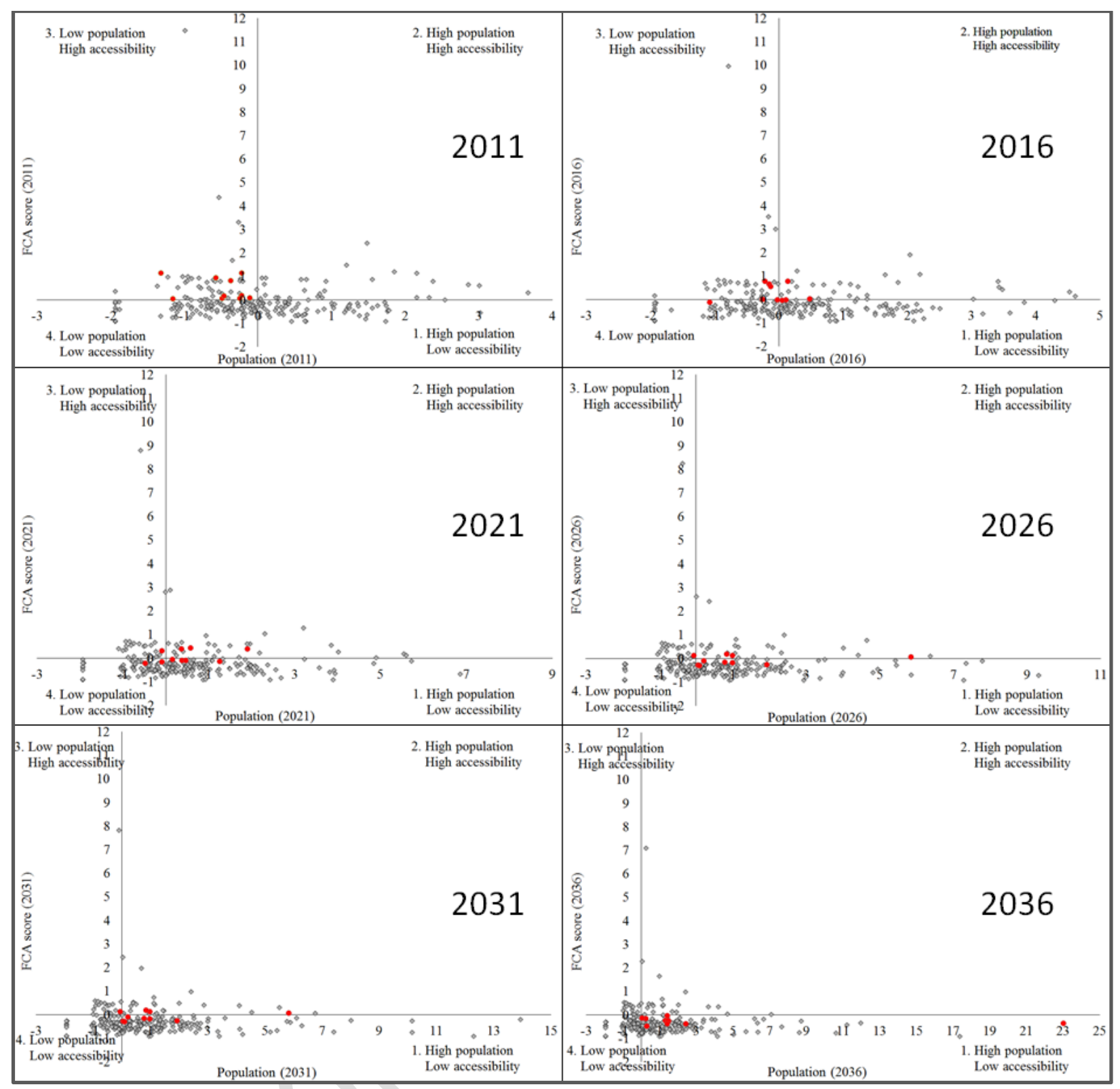

Figure 7 Quadrant plots - fire service accessibility and medium series population estimates (2011 to 2036)

Table 5 Number (per cent) of locales transiting from 2011 quadrants to 2036 quadrants - using medium series SA2 population estimates

\begin{tabular}{|c|c|c|c|c|c|}
\hline \multirow{2}{*}{2011 quadrants } & \multicolumn{4}{|c|}{2036 quadrants } & \\
\hline & $\begin{array}{l}1 \text { (High Pop - } \\
\text { Low FCA) }\end{array}$ & $\begin{array}{c}2 \text { (High Pop - } \\
\text { High FCA) }\end{array}$ & $\begin{array}{l}3 \text { (Low Pop } \\
\text { High FCA) }\end{array}$ & $\begin{array}{l}4 \text { (Low Pop - } \\
\text { Low FCA) }\end{array}$ & $\begin{array}{l}\text { Total } \\
\text { Locale }\end{array}$ \\
\hline $1(\mathrm{High}$ Pop - Low FCA & $72(31.30)$ & 0 & 0 & 0 & $72(31.30)$ \\
\hline 2 (High Pop - High FCA) & $17(7.39)$ & $10(4.35)$ & 0 & 0 & $27(11.74)$ \\
\hline 3 (Low Pop - High FCA) & $10(4.35)$ & $11(4.78)$ & $15(6.54)$ & $10(4.35)$ & $46(20)$ \\
\hline $4($ Low Pop - Low FCA $)$ & $39(16.96)$ & 0 & 0 & $46(20)$ & $85(36.96)$ \\
\hline Total Locale & $138(60)$ & $21(9.13)$ & $15(6.52)$ & $56(24.35)$ & 230 \\
\hline
\end{tabular}




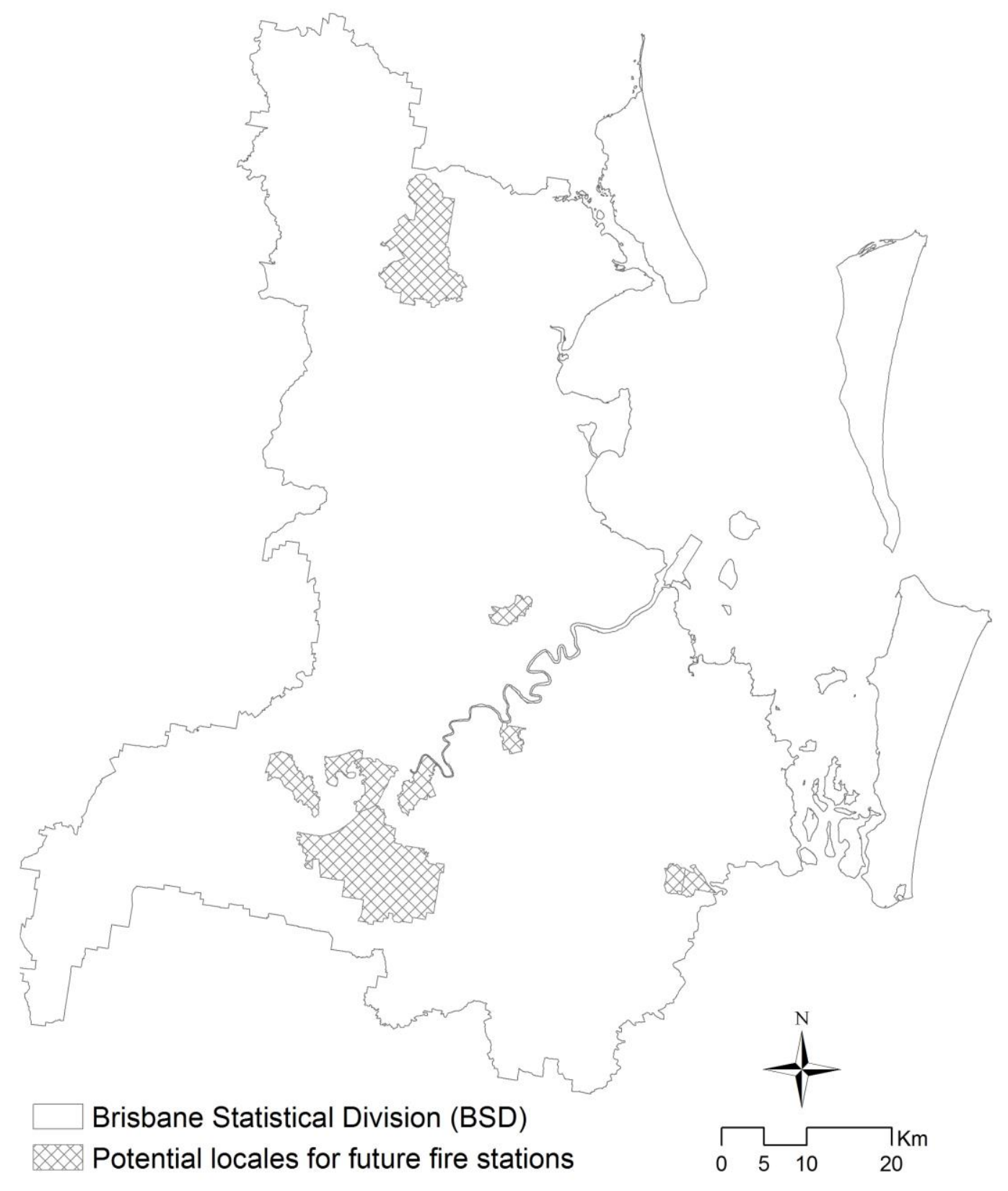

Figure 8 Potential locales for future fire stations

Demand projections (i.e., population forecasts) over long time horizons embed a certain degree of uncertainty that projects the likely trend into the future for which the population forecasts pertain. For this reason, we conduct a scenario-based analysis by examining two alternate population projection series, a low and high series ${ }^{5}$. Table 6 presents the number of locales transitioning quadrants

\footnotetext{
${ }^{5}$ We compute weights using the Greater Brisbane Greater Capital City Statistical Area (GCCSA) population projection data produced by QGSO. More specifically, drawing on population projection data series (i.e., low, medium and high), we derive weights (i.e., a ratio) from 2011 to 2036. These weights are then used to derive both the low and high series at the SA2-level using the medium SA2 series at the input population series.
} 
between 2011 and 2036 and compare these results to those presented in Table 5. Of particular interest are the locales that transition from quadrant 3 (i.e., locales with low populations and high fire service accessibility) to quadrant 1 (i.e., locales with high populations and low fire service accessibility) between 2011 and 2036. For the low series results reveal that only 8 locales transition between quadrant 3 and quadrant 1, which grow to 13 under the high series (Table 6). While the number of locales transitioning between quadrants is found to vary based on the input population series, the locales identified remain the same to those identified in Table 5. The relationship between FCA scores and the low and high population series are presented in Appendix $A^{6}$.

Table 6 Number (per cent) of locales transiting from 2011 quadrants to 2036 quadrants using (a) low series SA2 population estimates (upper) and (b) high series SA2 population estimates (lower)

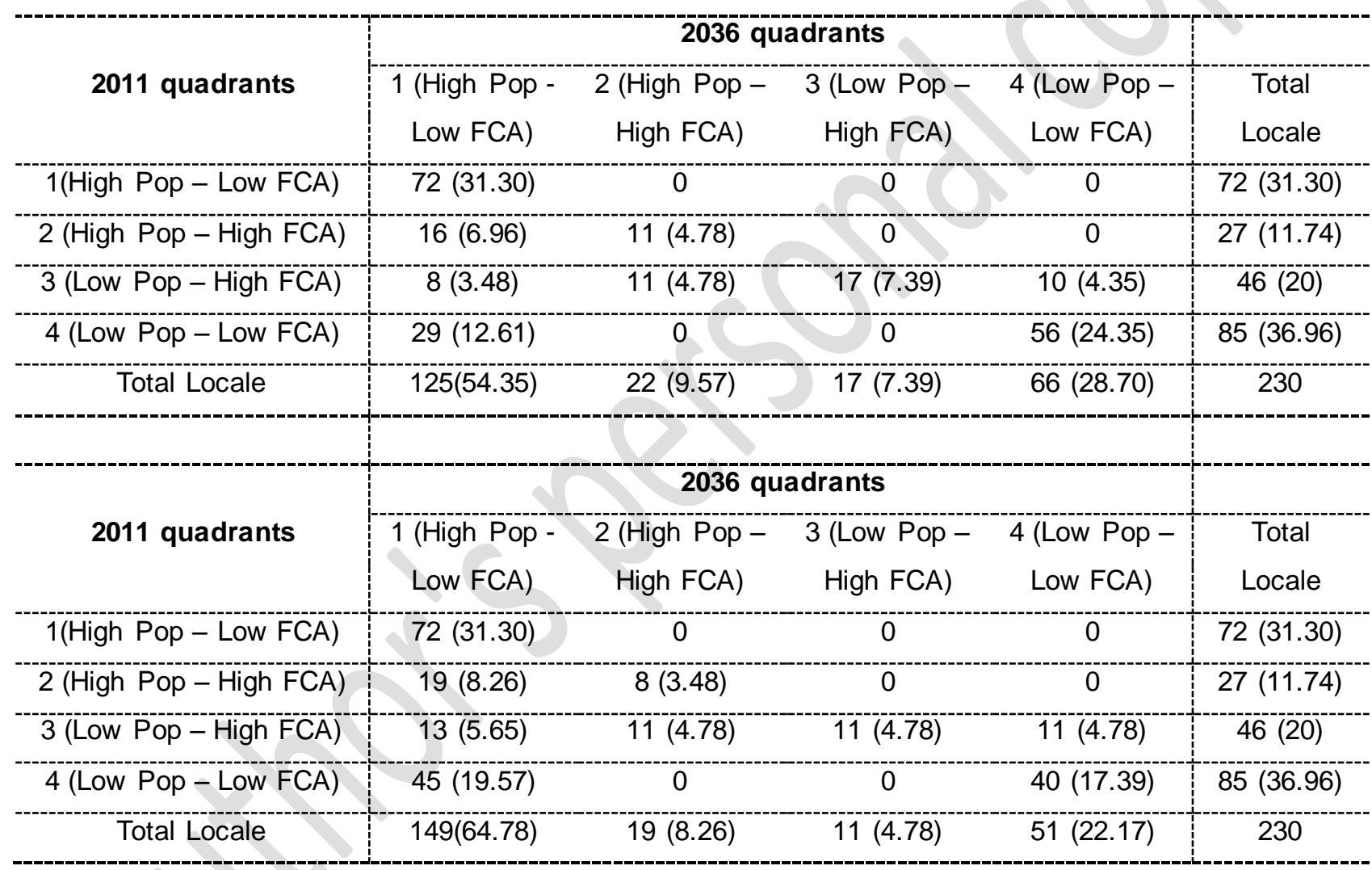

In summary, the results show spatial variation in fire service accessibility in the BSD, and that this variation is found to be negatively influenced by the distribution of population in the area. The findings captured through employing an enhanced FCA method are promising given their capacity to provide strong evidence to fire services and planning authorities where future fire resources (fire stations) could be targeted to respond to calls for fire services in the BSD.

\footnotetext{
${ }^{6}$ The FCA scores for each locale were computed using the 14-minute response time threshold and the vertical axis in Figures 9 and 10 represent the standardised value of fire service accessibility scores while the horizontal axis represent the standardised value of population estimates.
} 


\section{Conclusion}

This paper employed the enhanced two-step FCA method to examine the levels of spatial accessibility to fire services in Brisbane Statistical Division, Australia. The application of the enhanced FCA method tackled two common assumptions affecting the validity of traditional accessibility models: (i) all areas having equal accessibility to a fire station within the catchment, regardless of actual travel time (i.e. no consideration of distance-decay within a given catchment), and (ii) no accessibility outside the catchment, regardless of any differences in travel time. While incorporating the distance-decay parameter, it is the first study that measures and maps spatial variability in service accessibility related to demand for fire services using small area population forecasts.

The FCA technique has utility for emergency service providers. Methodologically, it enables the integration of multiple sources of information into a single, more useful and easy to understand index that permits comparisons across different locations within a region. It considers distance decay within catchments to compute accessibility. It is also enhanced with the ability to capcertain services based on population size or travel time threshold to improve the accuracy of previously formulated models. The utility of FCA from a practical perspective is its capacity to monitor fire service response provision (i.e., to ensure that the minimum standards of service level provision are achieved); its ability to measure the efficiency and coverage of existing service provision to maximise access and minimise operational costs (i.e., to assist in operational planning) and its capacity in computing the levels of spatial accessibility of population to fire services in relation to current and future populaton growth (i.e. the key strategy).. Its ability to map the likely levels of service coverage as a result of the spatial heterogeneity in predicted population growth clearly highlights its utility as a planning tool to inform the development of a strategic plan to improve operational efficiency of emergency response to minimise property loss, and reduce injuries and fatalities.

Similarly, the FCA technique is also useful to monitor the levels of spatial equity to ensure an equal access to all residents. The application of the FCA in this study identified areas that are most populated yet are of lower fire service accessibility. This finding would be difficult to detect through the use of traditional spatial proximity-based measures. Of particular interest to fire services and planning authorities are the areas of lower service accessibility and high population projected growth, which can be geotargeted for implementing policy and plans to improve future service delivery (e.g. building new fire stations). Our findings show that spatial accessibility of population to fire services over the period to 2036 is likely to reduce as a consequence of increases in demand. Results revealed a total of 10 areas, particularly from the Southern part of the BSD that are more likely to suffer a reduction in spatial accessibility than others. The results provide new evidence to inform 
future policy and planning related to location and allocation of new fire stations using the spatial accessibility as a decision criterion.

The findings of this study have two principal planning implications. The first is to help devise spatiallytargeted strategies for service expansion in areas of lower spatial accessibility to fire services, and the second is to enhance emergency resource planning through alignment with future population growth. The burgeoning demand for emergency services in rapidly growing areas necessitates further territorial expansion of fire service levy boundary in locations via establishing new fire stations to improve spatial coverage. Although the existing fire stations largely satisfy the increased demand within the BSD; yet there are some locales that are less adequately covered within a 14-minutes service delivery threshold. These locales have relatively lower levels of spatial accessibility to the nearest fire service station.

The approach adopted in this study however is not without limitations. The first is the use of BSD as a single case study, which might affect the generalisability of results to other urban contexts and interoperability of the FCA method. The second is the spatial granularity of the population forecasts at the SA2 level used to estimate the demand for emergency services. Future studies could draw on forecasted dwelling counts at a small area level. While this study conducted fire service accessibility analysis using the aggregate population data available at the SA2 level, given the availability of population forecasts at a more finer spatial granularity, the results can be grounded at a local area level to help support the better allocation of future fire stations. Future research is now needed to investigate the extent to which this methodology can be replicated in other developed city contexts or emergency services such as police and ambulance and in doing so would create a larger knowledge base to support informed decision-making. 
6. Appendix A: - Scenario-based analysis using low and high series population estimates

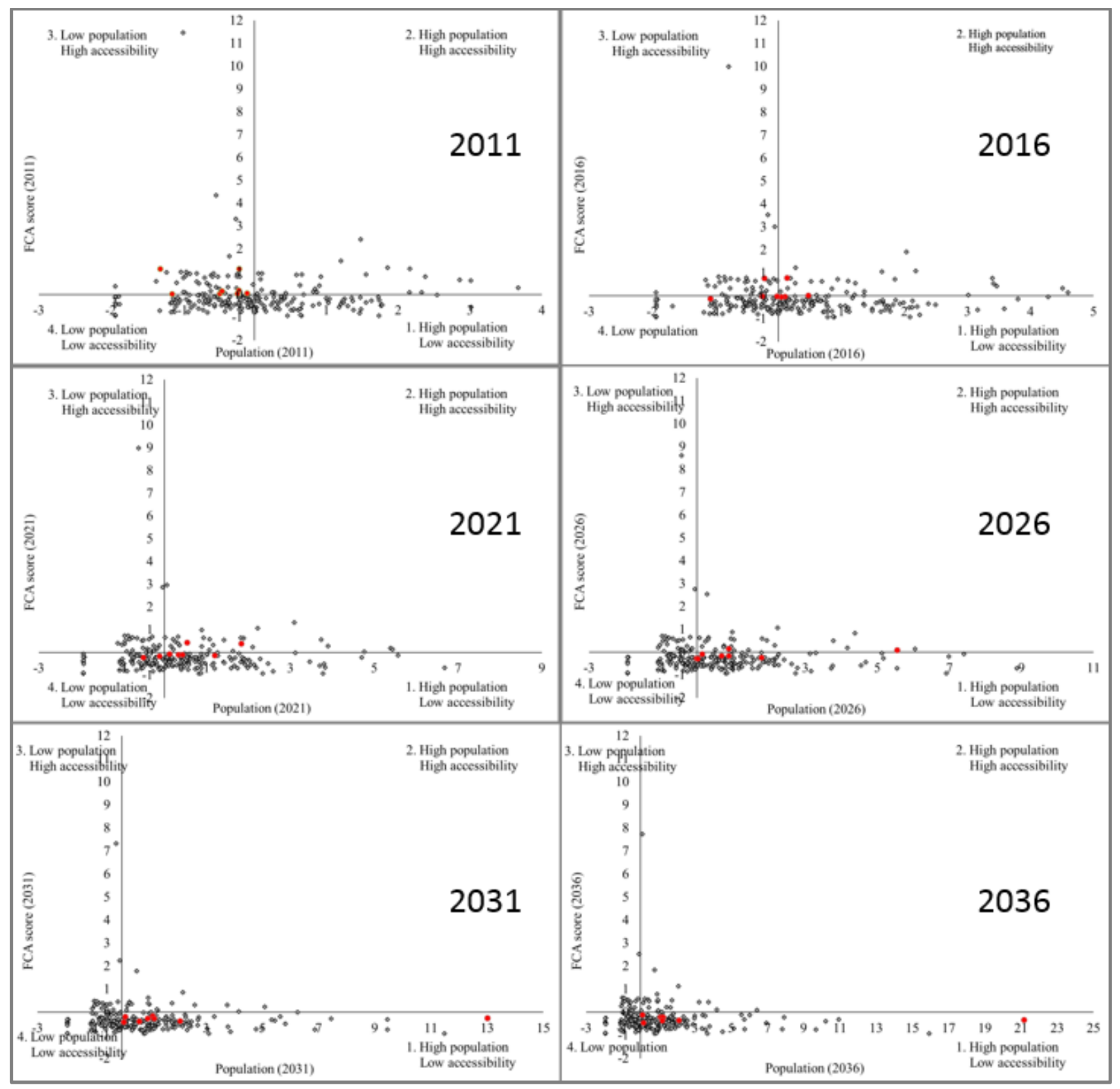

Figure 9 Quadrant plots - fire service accessibility and low series population estimates (2011 to 2036) 


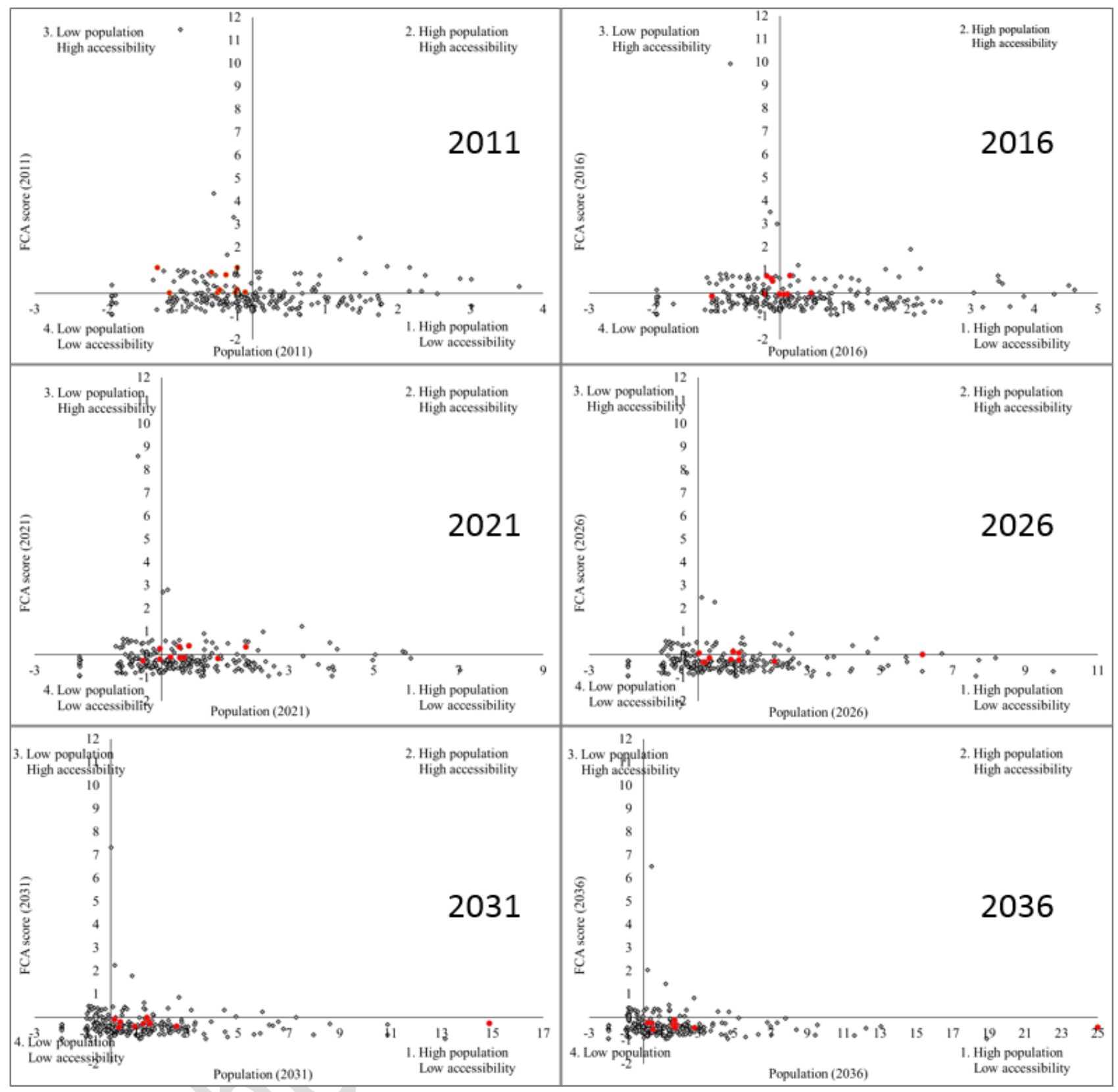

Figure 10 Quadrant plots - fire service accessibility and high series population estimates (2011 to 2036) 


\section{Acknowledgements}

We would like to thank the Queensland Fire and Emergency Service (QFES) for access to the data on which the paper is based. We would also like to thank the anonymous reviewers whosecomments were very helpful in improving the quality of this paper. The interpretations of the analysis are solely those of the authors and do not necessarily reflect the views and opinions of QFES or any of their employees. 


\section{References}

ABS 2011, Australian Statistical Geography Standard (ASGS): Volume 1 - Main Structure and Greater Capital City Statistical Areas Australia July -

http://www.ausstats.abs.gov.au/Ausstats/subscriber.nsf/0/D3DC26F35A8AF579CA2578010 00DCD7D/\$File/1270055001_july\%202011.pdf, Accessed 4th June 2017.

ABS 2014, ABS regional population growth, http://www.abs.gov.au/AUSSTATS/abs@.nsf/Previousproducts/3218.0Main\%20Features15 2013-14?opendocument\&tabname, Accessed 4th June 2017

Aktaş, E, Özaydın, Ö, Bozkaya, B, Ülengin, F \& Önsel, Ş 2013, 'Optimizing fire station locations for the Istanbul metropolitan municipality', Interfaces, vol. 43, pp. 240-255.

Ansari, S, Yoon, S \& Albert, LA 2017, 'An approximate hypercube model for public service systems with co-located servers and multiple response', Transportation Research Part E: Logistics and Transportation Review, vol 103, pp.143-157.

Badri, MA, Mortagy, AK \& Alsayed, CA 1998, 'A multi-objective model for locating fire stations', European Journal of Operational Research, vol. 110(2), pp. 243-260.

Bagheri, N, Benwell, GL \& Holt, A 2006, 'Primary Health Care Accessibility for Rural Otago: A Spatial Analysis', HIC 2006 and HINZ2006: Proceedings, p.365.

Ball, M., and Lin, F., 1993, 'A reliability model applied to emergency service vehicle location," Operations Research, vol. 41-1, pp.18-36.

Başar, A, Çatay, B \& Ünlüyurt, T 2012, 'A taxonomy for emergency service station location problem', Optimization Letters, vol. 6, pp. 1147-1160.

Batta, R., and Mannur, N., 1990, 'Covering-location models for emergency situations that require multiple response units,' Management Science, vol. 36-1, pp. 16-23.

Batta, R, Dolan, J \& Krishnamurthy, N 1989, 'The maximal expected covering location problem: Revisited', Transportation Science, vol. 23, pp. 277-287.

Bertolini, L, Le Clercq, F \& Kapoen, L 2005, 'Sustainable accessibility: a conceptual framework to integrate transport and land use plan-making. Two test-applications in the Netherlands and a reflection on the way forward', Transport policy, vol. 12(3), pp.207-220.

Bhat, C, Handy, S, Kockelman, K, Mahmassani, H, Chen, Q \& Weston, L 2000, 'Urban accessibility index: literature review', Center of Transportation Research, University of Texas at Austin, Springfield.

Braidwood, J 1866, 'Fire Prevention and Fire Extinction... With illustrations, memoir, and portrait of the author', Bell \& Daldy.

Bruinsma, F \& Rietveld, P 1998, 'The accessibility of European cities: theoretical framework and comparison of approaches', Environment and Planning A, vol. 30(3), pp.499-521.

BTS 1997, 'Transportation Statistics Annual Report', Bureau of Transportation Statistics, US Department of Transportation, Washington, DC 
Burns, LD 1979, 'Transportation, temporal, and spatial components of accessibility'. Lexington Books, Lexington (MA), USA.

Butterworth, S 1930, 'On the theory of filter amplifiers', Wireless Engineer, vol. 7(6), pp.536-541.

Catay, B 2011, 'Siting new fire stations in Istanbul: A risk-based optimization approach', OR Insight, vol. 24(2), pp. 77-89.

Challands, N 2010, 'The relationships between fire service response time and fire outcomes'. Fire technology, 46(3), pp. 665-676.

Chevalier, P, Thomas, I, Geraets, D, Goetghebeur, E, Janssens, O, Peeters, D \& Plastria, F 2012, 'Locating fire stations: an integrated approach for Belgium', Socio-Economic Planning Sciences, vol. 46(2), pp. 173-182.

Chevalier, P, Thomas, I, Geraets, D, Goetghebeur, E, Janssens, O, Peeters, D \& Plastria, F 2012, 'Locating fire stations: an integrated approach for Belgium', Socio-Economic Planning Sciences, vol. 46, no. 2, pp. 173-182.

Chhetri, P, Corcoran, J, Ahmad, S, KC, K 2018, 'Examining spatio-temporal patterns, drivers and trends of residential fires in South East Queensland, Australia', Disaster Prevention and Management, https://doi.org/10.1108/DPM-09-2017-0213

Chhetri, P, Corcoran, J \& Stimson, R 2009, 'Exploring the spatio-temporal dynamics of fire incidence and the influence of socio-economic status: a case study from South East Queensland, Australia', Journal of Spatial Science, vol. 54, pp. 79-91.

Church, R \& ReVelle, C 1974, 'The maximal covering location problem', Papers of the Regional Science Association, vol. 32, pp. 101-118.

Curtis, C \& Scheurer, J 2010, 'Planning for sustainable accessibility: Developing tools to aid discussion and decision-making', Progress in Planning, vol. 74(2), pp.53-106.

Dai, D \& Wang, F 2011, 'Geographic disparities in accessibility to food stores in southwest Mississippi', Environment and Planning B: Planning and Design, vol. 38(4), pp.659-677.

Dai, D 2010, 'Black residential segregation, disparities in spatial access to health care facilities, and late-stage breast cancer diagnosis in metropolitan Detroit', Health \& place, vol. 16(5), pp.1038-1052.

Dai, D 2011, 'Racial/ethnic and socioeconomic disparities in urban green space accessibility: Where to intervene?', Landscape and Urban Planning, vol. 102(4), pp.234-244.

Dalvi, MQ \& Martin, KM 1976, 'The measurement of accessibility: some preliminary results', Transportation, 5(1), pp. 17-42.

Daskin, M 1983, 'A maximum expected covering location model: formulation, properties and heuristic solution', Transportation Science, vol. 17, pp. 48-70.

Daskin, MS \& Stern, EH 1981, 'A hierarchical objective set covering model for emergency medical service vehicle deployment', Transportation Science, vol. 15(2), pp.137-152. 
Degel, D, Wiesche, L, Rachuba, S \& Werners, B 2014, 'Reorganizing an existing volunteer fire station network in Germany', Socio-Economic Planning Sciences, vol. 48(2), pp. 149-157.

Dony, CC, Delmelle, EM \& Delmelle, EC 2015, 'Re-conceptualizing accessibility to parks in multimodal cities: A Variable-width Floating Catchment Area (VFCA) method', Landscape and Urban Planning, vol. 143, pp.90-99.

Farahani, RZ, Steadieseifi, M \& Asgari, N 2010, 'Multiple criteria facility location problems: A survey', Applied Mathematical Modelling, vol. 34, pp. 1689-1709.

Frew, R, Higgs, G, Harding, J \& Langford, M 2017, 'Investigating geospatial data usability from a health geography perspective using sensitivity analysis: The example of potential accessibility to primary healthcare', Journal of Transport \& Health.

Geurs, KT, \& Van Wee, B 2004, 'Accessibility evaluation of land-use and transport strategies: review and research directions', Journal of Transport geography, vol. 12(2), pp. 127-140.

Goldberg, J \& Paz, L, 1991, 'Locating Emergency Vehicle Bases When Service Time Depends on Call Location,' Transportation Science, vol. 25, pp. 264-280.

Guagliardo, MF 2004, 'Spatial accessibility of primary care: concepts, methods and challenges', International journal of health geographics, vol. 3(1), p. 1.

Hansen, WG 1959, 'How accessibility shapes land use', Journal of the American Institute of planners, vol. 25(2), pp. 73-76.

Higgs, G, Langford, M \& Norman, P 2015, 'Accessibility to sport facilities in Wales: A GIS-based analysis of socio-economic variations in provision', Geoforum, vol. 62, pp.105-120.

Higgs, G, Zahnow, R, Corcoran, J, Langford, M \& Fry, R 2017, 'Modelling spatial access to General Practitioner surgeries: Does public transport availability matter?', Journal of Transport \& Health.

Hogan, K \& ReVelle, C 1986, 'Concepts and applications of backup coverage', Management Science, vol. 32(11), pp.1434-1444.

Hogg, JM 1968, 'The Siting of Fire Stations', Operational Research Society, vol. 19, pp. 275-287.

Ingram, DR 1971, 'The concept of accessibility: a search for an operational form', Regional studies, vol. 5(2), pp.101-107.

Jarvis, J 1975, 'Optimization in Stochastic Systems with Distinguishable Servers', TR-19-75.

Joseph, AE \& Phillips, DR 1984, 'Accessibility and utilization: geographical perspectives on health care delivery', Sage.

Joseph, L \& Kuby, M 2011, 'Gravity modeling and its impacts on location analysis', In Foundations of location analysis, pp. 423-443, Springer US.

KC, K \& Corcoran, J 2017, 'Modelling residential fire incident response times: A spatial analytic approach', Applied Geography, vol. 84, pp.64-74. 
KC, K, Corcoran, J \& Chhetri, P 2018, 'Spatial Optimisation of Fire Service Coverage: A Case Study of Brisbane, Australia', Geographical Research, vol. 56(3), pp. (270-284), doi:10.1111/1745-5871.12288.

KC, K., Corcoran, J., Higginson, A. and Chhetri, P. (2015), "Temporal and spatial patterns of fire incident response time: a case study of residential fires in Brisbane", In State of Australian Cities Conference, State of Australian Cities Research Network.

Khan, AA 1992, 'An integrated approach to measuring potential spatial access to health care services', Socio-economic planning sciences, 26(4), pp.275-287.

Krockenberger, M 2015, 'Population growth in Australia', The Australia Institute: Canberra, Australia.

Langford, M \& Higgs, G 2006, 'Measuring potential access to primary healthcare services: the influence of alternative spatial representations of population', The Professional Geographer, vol. 58(3), pp.294-306.

Langford, M, Higgs, G \& Fry, R 2012, 'Using floating catchment analysis (FCA) techniques to examine intra-urban variations in accessibility to public transport opportunities: the example of Cardiff, Wales', Journal of Transport Geography, vol. 25, pp. 1-1

Langford, M, Higgs, G \& Fry, R 2016, 'Multi-modal two-step floating catchment area analysis of primary health care accessibility', Health \& place, vol. 38, pp.70-81.

Larson, RC 1974, 'A hypercube queuing model for facility location and redistricting in urban emergency services', Computers \& Operations Research, vol. 1, no. 1, pp. 67-95.

Larson, RC 1975, 'Approximating the performance of urban emergency service systems', Operations Research, vol. 23, no. 5, pp. 845-868.

Lee, E 2014, 'Designing Service Coverage and Measuring Accessibility and Serviceability of Rural and Small Urban Ambulance Systems', Systems, vol. 2(1), pp. 34-53.

Luo, W \& Qi, Y 2009, 'An enhanced two-step floating catchment area (E2SFCA) method for measuring spatial accessibility to primary care physicians', Health \& place, vol. 15(4), pp. 1100-1107.

Luo, W \& Whippo, T 2012, 'Variable catchment sizes for the two-step floating catchment area (2SFCA) method', Health \& place, vol. 18(4), pp.789-795.

Luo, W 2004, 'Using a GIS-based floating catchment method to ass ess areas with shortage of physicians', Health \& place, vol. 10(1), pp. 1-11.

Luo, W, \& Wang, F 2003, 'Measures of spatial accessibility to health care in a GIS environment: synthesis and a case study in the Chicago region', Environment and Planning B, vol. 30(6), pp. 865-884.

Marianov, V \& ReVelle, C 1996, 'The queueing maximal availability location problem: a model for the siting of emergency vehicles', European Journal of Operational Research, vol. 93(1), pp.110-120. 
McGrail, MR \& Humphreys, JS 2009, 'Measuring spatial accessibility to primary care in rural areas: improving the effectiveness of the two-step floating catchment area method', Applied Geography, vol. 29(4), pp. 533-541.

Marianov, V \& Serra, D, 2002, 'Location Problems in the Public Sector', In Drezner, Z. \& Hamacher, H, 2002, Facility Location Application and Theory, New York: Springer, pp. 119143.

Murray, A 2010, 'Advances in Location Modeling: GIS Linkages and Contributions', Journal of Geographical Systems, vol. 12, pp. 335-354

Murray, AT 2013, 'Optimising the spatial location of urban fire stations', Fire Safety Journal, http://dx.doi.org/10.1016/j.firesaf.2013.03.002.

Murray, AT 2015, 'Fire Station Siting', In Applications of Location Analysis, pp. 293-306, Springer, Cham.

Ngui, AN \& Apparicio, P 2011, 'Optimizing the two-step floating catchment area method for measuring spatial accessibility to medical clinics in Montreal', BMC health services research, vol. 11(1), p.1.

Nutley, SD 1980, 'Accessibility, mobility and transport-related welfare: the case of rural Wales', Geoforum, vol. 11(4), pp. 335-352.

Peng, ZR 1997, 'The jobs-housing balance and urban commuting', Urban studies, vol. 34(8), pp.1215-1235.

Pérez, J, Maldonado, S \& Marianov, V 2016, 'A reconfiguration of fire station and fleet locations for the Santiago Fire Department', International Journal of Production Research, vol. 54(11), pp. 3170-3186.

Pooler, J 1987, 'Measuring geographical accessibility: a review of current approaches and problems in the use of population potentials', Geoforum, vol. 18(3), pp. 269-289.

Productivity Commission 2015, Report on Government Services 2015, http://www.pc.gov.au/research/recurring/report-on-government-services/2015/emergencymanagement/fire-and-ambulance-services/rogs-2015-volumed-chapter9.pdf, Accessed 4th June 2017.

Queensland fire and emergency services 2014, Annual Report,

https://www.qfes.qld.gov.au/about/documents/QFES2013-14AnnualReport.pdf, Accessed $21^{\text {st }}$ September 2016.

Radke, J \& Mu, L 2000, 'Spatial decompositions, modeling and mapping service regions to predict access to social programs', Geographic Information Sciences, vol. 6(2), pp.105-112.

Rafi, MM, Wasiuddin, S \& Siddiqui, SH 2012, 'Assessment of fire hazard in Pakistan', Disaster Prevention and Management, vol. 21, pp. 71-84.

Reilly, WJ, 1931, 'The law of retail gravitation', WJ Reilly.

Scheurer, J \& Curtis, C 2007, 'Accessibility measures: Overview and practical applications', Department of Urban and Regional Planning, Curtin University, 52. 
Schreuder, JAM 1981, 'Application of a location model to fire stations in Rotterdam', European Journal of Operational Research, vol. 6(2), pp. 212-219.

Schuurman, N, Berube, M \& Crooks, VA 2010, 'Measuring potential spatial access to primary health care physicians using a modified gravity model', The Canadian Geographer, vol. 54(1), pp. 29-45.

Takeda, RA, Widmer, JA \& Morabito, R 2007, 'Analysis of ambulance decentralization in an urban emergency medical service using the hypercube queueing model', Computers \& Operations Research, vol. 34, no. 3, pp. 727-741.

The Geneva Association 2014, World fire statistics, information bulletin no. 29, Available at https://www.genevaassociation.org/media/874729/ga2014-wfs29.pdf, Accessed 4th June 2017.

The World Health Organization 2016, Violence and Injury Prevention - Burns, Available at http://www.who.int/violence_injury_prevention/other_injury/burns/en/, Accessed 4th June 2017.

Toregas, C, Swain, R, ReVelle, C, \& Bergman, L 1971, 'The location of emergency service facilities', Operations Research, vol. 19, no. 5, pp. 1363-1373.

van den Berg, PL \& Aardal, K 2015, 'Time-dependent MEXCLP with start-up and relocation cost', European Journal of Operational Research, 242(2), pp.383-389.

Vickerman, RW 1974, 'Accessibility, attraction, and potential: a review of some concepts and their use in determining mobility', Environment and Planning A, vol. 6(6), pp.675-691.

Wan, N 2011, Disparities of Colorectal Cancer Survival in Texas (Doctoral dissertation, Texas State University-San Marcos).

Wang, F \& Minor, WW 2002, 'Where the jobs are: employment access and crime patterns in Cleveland', Annals of the Association of American Geographers, vol. 92(3), pp.435-450.

Wang, F 2000, 'Modeling commuting patterns in Chicago in a GIS environment: A job accessibility perspective', The Professional Geographer, vol. 52(1), pp. 120-133.

Wang, F 2003, 'Job proximity and accessibility for workers of various wage groups', Urban Geography, vol. 24(3), pp. 253-271.

Weibull, JW 1976, 'An axiomatic approach to the measurement of accessibility', Regional science and urban economics, vol. 6(4), pp. 357-379.

Yang, DH, Goerge, R \& Mullner, R 2006, 'Comparing GIS-based methods of measuring spatial accessibility to health services', Journal of medical systems, vol. 30(1), pp. 23-32.

Zhang, X., Li, X. \& Hadjisophocleous, G, 2013, 'A probabilistic occupant evacuation model for fire emergencies using Monte Carlo methods', Fire Safety Journal, 58, pp.15-24. 